Brazilian Journal

of Chemical

Engineering

\title{
EVALUATION OF THE PHOTOCATALYTIC ACTIVITY OF SiO @TiO,HYBRID SPHERES IN THE DEGRADATION OF METHYLENE BLUE AND HYDROXYLATION OF BENZENE: KINETIC AND MECHANISTIC STUDY
}

\author{
Bruno C. B. Salgado ${ }^{1 *}$ and Antoninho Valentini ${ }^{2}$ \\ ${ }^{1}$ Instituto Federal de Educação, Ciência e Tecnologia do Ceará, Departamento de Química e Meio Ambiente, Maracanaú CE, Brasil. \\ E-mail: brunocesar@ifce.edu.br - ORCID: 0000-0002-9858-7836 \\ ${ }^{2}$ Universidade Federal do Ceará, Departamento de Química Analítica e Físico-Química, Fortaleza CE, Brasil. ORCID: 0000-0002-7019-6155
}

(Submitted: March 15, 2019 ; Revised: April 15, 2019 ; Accepted: April 18, 2019)

\begin{abstract}
Silica spheres coated with titania $\left(\mathrm{SiO}_{2} @ \mathrm{TiO}_{2}\right)$ were synthesized using chitosan as template. The $\mathrm{N}_{2}$ adsorption/desorption isotherms of the spheres point to meso and macroporous characteristics and the elemental mapping by EDS shows uniform distribution of Ti on the surface of the silica spheres, leading to formation of an amorphous structure (XRD). The results from the model reaction of photocatalytic degradation of methylene blue (MB) show a good stability of the spheres regarding their reuse. The tests with various additives pointed to hydroxyl radical production as the main via of $\mathrm{MB}$ degradation. The photocatalytic activity of the spheres in the hydroxylation of benzene to form phenol, hydroquinone and benzoquinone was assessed. The kinetic data point to the formation of phenol as the limiting step; in addition, the phenol consumption occurs by parallel and consecutive reactions producing benzoquinone.
\end{abstract}

Keywords: Silica sphere; Titania; Photocatalysis; Hydroxylation.

\section{INTRODUCTION}

Heterogeneous photocatalysis is applied in several reaction systems, especially for oxidation reactions of organic pollutants present in the air (Augugliaro et al., 1999; Adamczyk and Długoń, 2012) or wastewater (Ahmed et al., 2011; Vela et al., 2012; Affam and Chaudhuri, 2013). However, it is also applied for the synthesis of compounds by oxidative (Park and Choi, 2005) or reductive (Maldotti et al., 2000) pathways.

The fundamental concepts of the photocatalytic process are based on photonic excitation of a semiconductor material by means of an irradiation source with energy higher than the band-gap of the semiconductor. When there is enough energy, the promotion of an electron from the valence band $(\mathrm{vb})$ to the conduction band $(\mathrm{cb})$ will occur, forming the pair electron/hole $\left(e_{c b}{ }^{-1} h_{v b}{ }^{+}\right)$. Once formed, the electron/hole can either recombine or react with species adsorbed on the surface of material, which may be either an electron donor (e.g. hydroxide ions) or electron acceptor (e.g., molecular oxygen). This process results in the formation of highly reactive substances such as the hydroxyl $\left({ }^{\circ} \mathrm{OH}\right)$ and superoxide $\left(\mathrm{O}_{2}^{-{ }^{-}}\right)$radicals (Wilhelm and Stephan, 2007).

A semiconductor material that has shown good quantum yield in photocatalytic processes is titanium dioxide $\left(\mathrm{TiO}_{2}\right)$, specifically in its anatase phase. $\mathrm{TiO}_{2}$ has been extensively used as photocatalyst due to its non-toxicity, low cost and photochemical stability (Fujishima et al., 2000; Chen and Mao, 2007).

The catalytic sample may present various morphological forms such as powder or in pellets. It is known that the material when finely divided provides

\footnotetext{
* Corresponding author: Bruno C. B. Salgado - E-mail: brunocesar@ifce.edu.br
} 
better contact with the substrate in solution. However, the use of this material in powder form may not be feasible for large scale since (Li et al., 2008) in this condition the separation step and consequently the reuse of the sample becomes expensive (Lee et al., 2008).

A possible way to avoid this issue is to apply materials with higher surface area as support for the active phase $\left(\mathrm{TiO}_{2}\right)$. In this perspective, silica $\left(\mathrm{SiO}_{2}\right)$ has properties that make it attractive as it is chemically inert, thermally stable, transparent to UV irradiation and presents high surface area (Bellardita et al. 2010; de Cordoba et al. 2019). Results observed by . Anderson and Bard (1997) suggests that, in the photocatalytic process employing mixed oxides of silica-titania, the substrate adsorption step assumes great relevance. It is suggested that the presence of $\mathrm{SiO}_{2}$ promotes the substrate pre-concentration on the surface of the material, which results in higher accessibility to photoexcited $\mathrm{TiO}_{2}$ present on the surface of the photocatalyst (Anderson and Bard, 1997). Several researchers have carried out studies of the application of composite materials $\left(\mathrm{TiO}_{2} / \mathrm{SiO}_{2}\right)$ in photocatalytic processes, especially for the degradation of organic substances (Yamashita et al., 1998; Hu et al., 2003; Malinowska et al., 2003; Chen et al., 2004; Zhang et al., 2006; Marugán et al., 2007; Wilhelm and Stephan, 2007; Lee et al., 2008; Maldotti et al., 2008; Bellardita et al., 2010; Matos et al., 2018; de Cordoba et al., 2019).

Wilhelmand Stephan(2007) performed the synthesis of nano-spheres $\mathrm{SiO}_{2} @ \mathrm{TiO}_{2}$ by heterocoagulation. By evaluating the effect of sphere size, from 220 to $590 \mathrm{~nm}$ in diameter, in the photocatalytic degradation of Rhodamine $\mathrm{B}$, the authors observed that, the bigger the particle diameter, the lower the ratio of degradation. Furthermore, the separation step and reuse of the photocatalyst is easer due to the larger size and weight of the particle. Lee et al. (2008) reported the effect of successive impregnation of the titanium precursor on the silica spheres. The sample subjected to three successive impregnations, corresponding to 99.6\% covered area of the material, showed the best photocatalytic performance.

The synthesis of porous spheres using templating strategy is a methodology extensively used, which includes the use of surfactants, emulsions and both copolymer and nanoporous blocks (Kadib et al., 2011). A recent research described the use of chitosan as an alternative template (Preethi et al., 2014). Chitosan is obtained by alkaline deacetylation of chitin (Liu et al., 2004), which is an abundant biopolymer found in the exoskeleton of crustaceans and insects. Chitosan ((1,4)-2-amino-2-deoxy-D-glucosamine), is a hydrophilic and biocompatible polymer which presents solubility in acidic medium; thus featuring various applications (Somashekar and Joseph, 1996).
Chitosan can also coordinate with metal ions due to the large number of active hydroxyl $(\mathrm{OH})$ and amino $\left(\mathrm{NH}_{2}\right)$ groups (Guibal, 2004). Hence, chitosan has been extensively used as a polymeric template for synthesis of materials (Wang et al., 2005; Chen et al., 2008; Malhotra and Kaushik, 2009; Jiang et al., 2012, 2014; Xiao et al., 2015). The chitosan property of being soluble in acid and insoluble in alkaline medium is important to make it applicable for the sphere synthesis. Accordingly, if a solution ( $\mathrm{pH}$ below 5 ) containing chitosan is added dropwise to a second solution with $\mathrm{pH}$ above 6.5 , under suitable agitation, the formation of biopolymer spheres is observed (Braga et al., 2009b, 2009a; Santos et al., 2015). This property makes chitosan applicable to the synthesis of oxide spheres; the addition of metal ions (e.g., $\mathrm{Al}^{3+}$ and $\mathrm{Fe}^{3+}$ ) into the solution containing the biopolymer is necessary. The spheres formed are composed of the polymer and the metal hydroxide (Braga et al., 2009b, 2009a; Santos et al., 2015), and the subsequent calcination leads the metal oxide to the spherical shape.

In order to exploit this property of chitosan, results are presented on the development of porous silica spheres coated with titania for photocatalytic applications. The photocatalytic activity of samples in the degradation of methylene blue dye was assessed by changing the initial concentration of dye and the effect of various additives (free radical scavenger) was evaluated on the reaction kinetics.

As previously mentioned by several authors (Marugán et al., 2007; Vela et al., 2012; Affam and Chaudhuri, 2013; Park et al., 2013), the use of photocatalysis to solve the wastewater contaminant problem or organic substance degradation can be an interesting research area. However, photocatalysis can also be used in the selective conversion of organic derivatives by oxidative or reductive route..

Phenol is an important industrial chemical due to its wide usage such as precursor of phenolic resins (i.e., bakelite). Phenol is also used for bisphenol-A synthesis, a precursor for the production of polycarbonates and epoxide resins. Phenol is produced from benzene by the cumene process (Park and Choi, 2005), which is not an environmentally friendly system. An interesting alternative route for phenol production is the photocatalytic process, which can produce phenol directly from benzene by a hydroxylation reaction (Zhang et al., 2011). The subsequent hydroxylation is difficult to avoid; but phenol partial oxidation produces hydroquinone which is also an important industrial chemical widely used (Buzzo et al., 2015).

Therefore, the benzene hydroxylation reaction to produce phenol, hydroquinone and benzoquinone is an interesting system to test the photocatalytic activity of the spheres for application in selective conversion reactions. 


\section{MATERIALS AND METHODS}

\section{Synthesis of $\mathrm{SiO}_{2}$ spheres coated with $\mathrm{TiO}_{2}$}

The synthesis procedure consisted of preparing hybrid spheres composed of chitosan (CTS), tetraethylorthosilicate (TEOS, $\mathrm{Si}\left(\mathrm{OC}_{2} \mathrm{H}_{5}\right)_{4}, 98 \%$, Aldrich) and silica ( $\mathrm{SiO}_{2}$, Aerosil $\AA$, Degussa Evonik) (Braga et al., 2009a) followed by calcination. The spheres were subjected to an impregnation process with titanium isopropoxide ( $\mathrm{Ti}(\mathrm{iPrO})_{4}, 97 \%$, Aldrich) and subsequent calcination.

For the synthesis of $\mathrm{SiO}_{2}$ spheres, an aqueous solution of chitosan $(3 \% \mathrm{w} / \mathrm{v})$, was prepared in acetic acid $(5 \% \mathrm{v} / \mathrm{v})(99.7 \%$ Vetec). The solution was kept under continuous stirring at room temperature until complete dispersion of the organic polymer. In parallel, a solution of TEOS in ethanol (95\%, Vetec) was prepared, followed by addition of $\mathrm{SiO}_{2}$ (Aerosil). The dispersion, containing equivalent amounts of moles of $\mathrm{Si}$ derived from two sources (TEOS and $\mathrm{SiO}_{2}$ ), was added to the chitosan solution under constant agitation, forming the CTS-Si mixture in a molar ratio of 1 to 1.5. The CTS-Si mixture was added dropwise into an aqueous solution of $\mathrm{NH}_{4} \mathrm{OH}(30 \%$ Vetec) with the aid of a peristaltic pump. The gelatinous spheres remained in the $\mathrm{NH}_{4} \mathrm{OH}$ solution for 12 hours, and then they were removed and left to dry at room temperature for 72 hours. Thereafter the spheres were calcined at $550{ }^{\circ} \mathrm{C}$ under flowing air for 3 hours with a heating rate of $5{ }^{\circ} \mathrm{C} / \mathrm{min}$. This procedure removed the organic material, forming the $\mathrm{SiO}_{2}$ spheres.

For the synthesis of the photocatalyst, $1.0 \mathrm{~mL}$ of $\mathrm{Ti}(\mathrm{iPrO})_{4}$ was diluted in $20.0 \mathrm{~mL}$ of isopropyl alcohol containing $1.0 \mathrm{~g}$ of silica spheres. The spheres remained in contact with this solution for 24 hours under constant agitation; after this period the spheres were removed and left to dry ( 24 hours at room temperature). The titanium dioxide crystallization occurred by calcination at $500{ }^{\circ} \mathrm{C}$ for 3 hours under a heating rate of $5^{\circ} \mathrm{C} / \mathrm{min}$. The spheres made by this method were denoted as $\mathrm{SiO}_{2} @ \mathrm{TiO}_{2}$.

\section{Photocatalyst characterization}

The X-ray diffraction (XRD) pattern was measured on a PANalytical XPert Pro MPD diffractometer. Measurements were obtained in an angular range of $10-90^{\circ}(2 \theta)$ using $\mathrm{Cu} \mathrm{K} \alpha(40 \mathrm{kV}$ and $45 \mathrm{~mA}$ ) radiation. The specific surface area (BET method) of the samples was determined from $\mathrm{N}_{2}$ adsorption/desorption isotherms, with the samples being previously outgassed under reduced pressure at $200{ }^{\circ} \mathrm{C}$ for 2 hours. Scanning electron microscopy measurements were taken in a FEG model Quanta 450 equipment with EDS/EBDS operating at $10 \mathrm{kV}$ and $2.27 \times 10^{-7}$ $\mathrm{Pa}$. The samples were placed on double-sided carbon tape on an aluminum support and metallized with gold in an argon atmosphere at low pressure. The infrared spectrum (FTIR) of spheres was performed with a 100 Spectrum (Perkin Elmer) system, in the range of $400-4500 \mathrm{~cm}^{-1}$ by using $\mathrm{KBr}$ pellets containing $0.1 \%$ (wt) of the sample, with a resolution of $4 \mathrm{~cm}^{-1}$. The point of zero charge (PZC) was determined from measurements of electric potential in the bilayer of the spheres via automatic titration with $\mathrm{HCl}$ or $\mathrm{NaOH}$ in a particle analyzer ZS90 Zetasizer Nano (Malvern). The diffuse reflectance spectrum (DRS) was obtained from a Thermo Evolution 300 system, performing a spectral scan of 300 to $800 \mathrm{~nm}$.

\section{Photocatalytic activity test}

The photocatalytic assays for methylene blue (MB) degradation were carried out in a cylindrical glass reactor with a total volume of $700 \mathrm{~mL}$ operated in batch mode, with $500 \mathrm{~mL}$ of $\mathrm{MB}$ aqueous solution, as shown in Figure 1. The reactor is equipped with a thermostatic jacket and water flowing around the outer wall and it has a low-pressure mercury lamp (Philips, $5 \mathrm{~W}, \mathrm{UV}-\mathrm{C}, 254 \mathrm{~nm}$ ) allocated in a quartz tube in the center of the reactor. The bottom of the reactor is conical with a sintered glass plate underneath, through which there was injection of atmospheric air with the aid of a pneumatic pump to the sphere suspension. The amount of photocatalyst used was $0.5 \mathrm{~g} / \mathrm{L}$, and the suspension was aerated under turbulent flow.

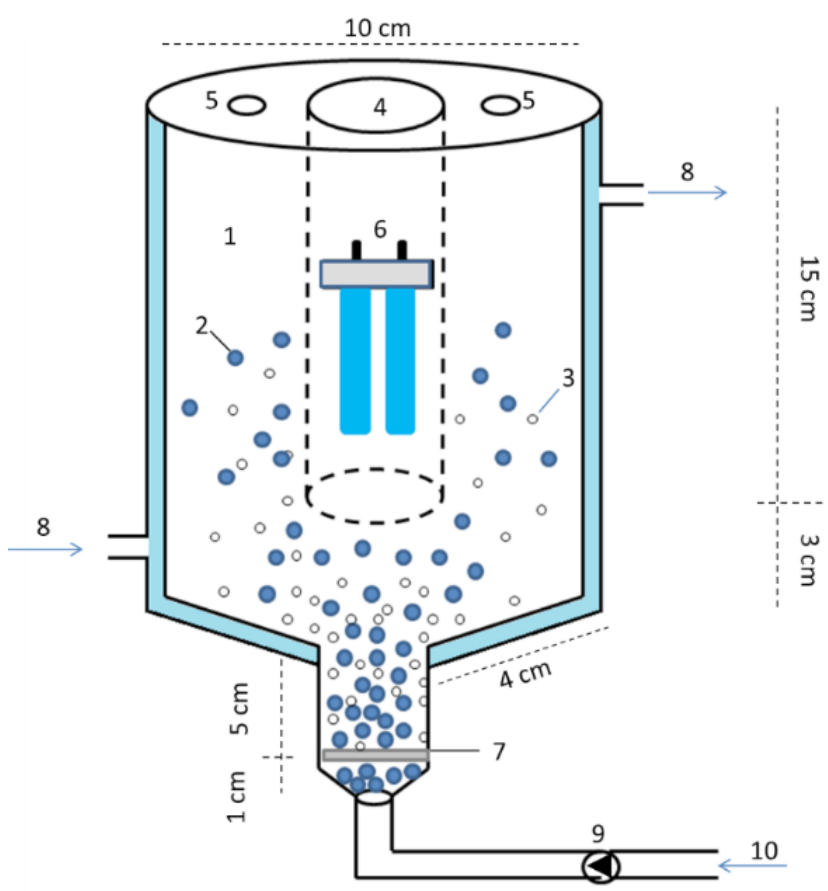

Figure 1. Scheme of the photocatalytic reactor used in the photodegradation of methylene blue. 1 - volume of solution, 2 - air bubbles, 3 - SiO $@ \mathrm{TiO}_{2}$ spheres, 4 - quartz tube, 5 - collection for analysis, 6 - UV-C lamp, 7 - sintered glass plate, 8 - water circulation, 9 pneumatic pump, 10 - atmospheric air intake. 
Aliquots of $3.5 \mathrm{~mL}$ of aqueous solution were collected at pre-established times and their absorbance promptly measured in a UV-vis spectrophotometer (Thermo) at $664 \mathrm{~nm}$. At the end of each analysis, the collected volume was returned to the reactor.

The photocatalytic hydroxylation of benzene was carried out in a closed reactor with reaction volume of $75 \mathrm{ml}$ equipped with a quartz tube centred in its cover, as shown in Figure 2. The reaction was performed in an aqueous suspension containing benzene and acetonitrile as co-solvent. The $\mathrm{SiO}_{2} @ \mathrm{TiO}_{2}$ spheres $(0.75 \mathrm{~g})$ were added to an aqueous solution of benzene $(11.7 \mathrm{mM})$ containing $70 \mathrm{ml}$ of water and $5 \mathrm{ml}$ of acetonitrile. The reactor was immediately closed and kept under constant stirring. In order to minimize benzene volatilization, acetonitrile was used as co-solvent in addition to the complete filling of the reactor volume. A high pressure mercury lamp (Golden, $5 \mathrm{~W}, \mathrm{UV}-\mathrm{A}, 365 \mathrm{~nm}$ ) was used in this test to avoid the photolytic decomposition of benzene. The monitoring of benzene conversion and production of phenol and its derivatives was performed by HPLC (Thermo) dual channel (254 and $270 \mathrm{~nm}$ ), using a $\mathrm{C} 18$ column $(5 \mu$ Phenomenex). The mobile phase consisted of methanol and formic acid $0.1 \%$ with the elution gradient of methanol as follows: $0-8$ $\min (30 \%$ to $50 \%$ ), $8-10 \mathrm{~min}$ (50\% to $80 \%$ ), $10-15 \mathrm{~min}$ $(80 \%)$ and $15-17 \mathrm{~min}(80 \%$ to $30 \%)$.

Mathematical models of photocatalytic kinetics were obtained by adjusting equation parameters in

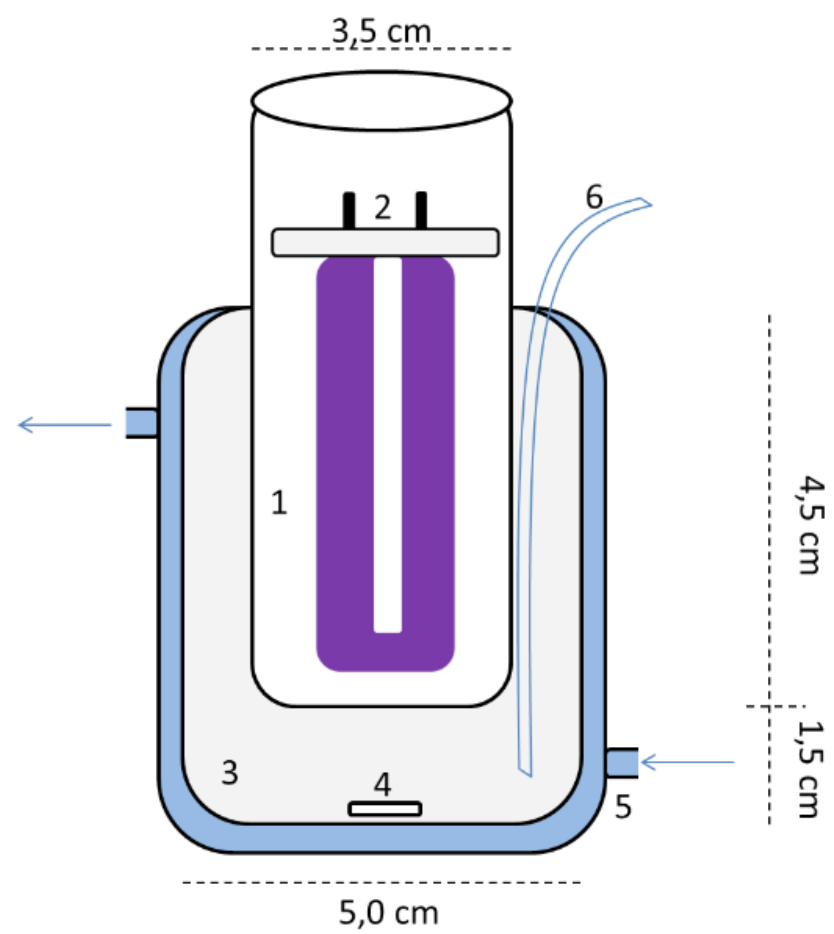

Figure 2. Scheme of the photocatalytic reactor used in the conversion of benzene. 1 - quartz tube, 2 - UV-A lamp, 3 - benzene solution, 4 - magnetic bar, 5 - water circulation, 6 - plastic tube for collection. their non-linear forms, aiming to minimize the sum of squared errors (SSE).

\section{RESULTS}

\section{Textural properties}

The $\mathrm{N}_{2}$ adsorption/desorption isotherms and the pore diameter distribution are shown in Figure 3 . The profiles obtained point to a lower amount of $\mathrm{N}_{2}$ adsorption due to the addition of $\mathrm{TiO}_{2}$, which should result in a lower surface area as well as lower pore volume. However, for both samples, the isotherms showed profiles that suggest morphological characteristics represented by the mixture of types II and III (IUPAC) and a low hysteresis of type H3, which may be due to pores in the slot shape.

The data presented in Table 1 summarize the analysis of the isotherms (Figure 3). As shown in Table 1 , the addition of $\mathrm{TiO}_{2}$ on silica spheres resulted in a significant decrease of the specific surface area and pore volume.

Nevertheless, the decreased pore volume is followed by the maintenance of the pore diameter distribution profile (Figure 3, insert). This result suggests that $\mathrm{TiO}_{2}$ is homogeneously dispersed. That means the data point to the presence of $\mathrm{TiO}_{2}$ throughout the $\mathrm{SiO}_{2}$ surface in the micro, meso or macro pores. A high $\mathrm{TiO}_{2}$ distribution is interesting, since particles of large diameter lead to a lower photocatalytic performance. The profiles show the presence of micropores (pores $<$

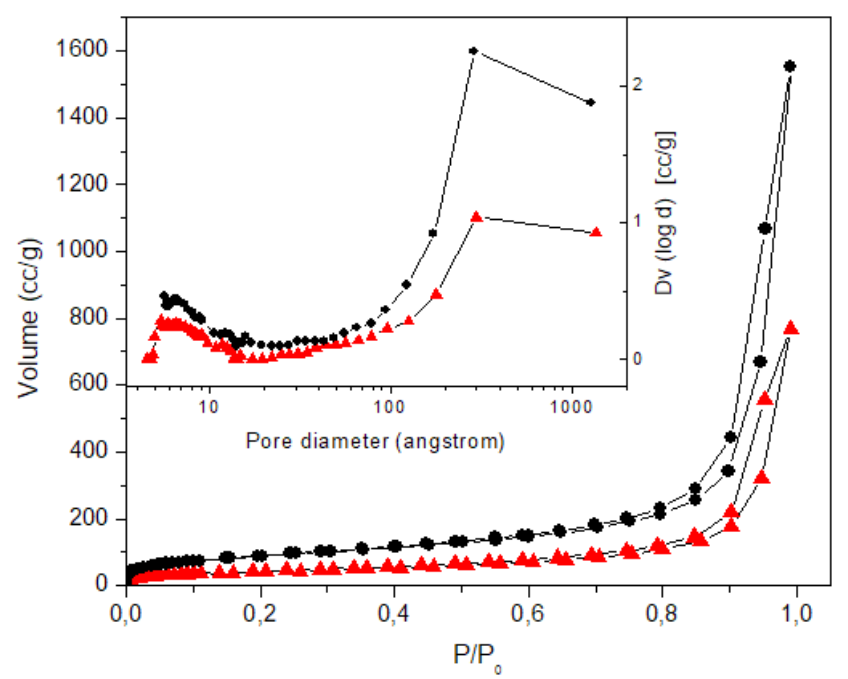

Figure 3. $\mathrm{N}_{2}$ adsorption/desorption isotherms and pore diameter distribution (insert) of $\mathrm{SiO}_{2}(\bullet)$ and $\mathrm{SiO}_{2} @$ $\mathrm{TiO}_{2}(\boldsymbol{\Delta})$ spheres.

Table 1. Specific surface area and pore volume of the spheres from $\mathrm{N}_{2}$ adsorption/desorption isotherms.

\begin{tabular}{ccc}
\hline Material & $\mathbf{S}_{\text {BET }}\left(\mathbf{m}^{2} / \mathbf{g}\right)$ & $\mathbf{V}^{*}\left(\mathbf{c m}^{3} / \mathbf{g}\right)$ \\
\hline $\mathrm{SiO}_{2}$ & 317 & 2.402 \\
$\mathrm{SiO}_{2} @ \mathrm{TiO}_{2}$ & 147 & 1.191 \\
\hline $\mathrm{V}^{*}$ - pore volume determined at $\mathrm{P} / \mathrm{P}_{0}=0.995$. &
\end{tabular}


$20 \AA$ ) and also pores with a diameter in the range of 20 to $500 \AA$, which correspond to mesopores. However, the pore diameter distribution essentially points to the presence of macropores, as suggested by the isotherm profiles.

The sample containing $\mathrm{TiO}_{2}\left(\mathrm{SiO}_{2} @ \mathrm{TiO}_{2}\right)$ was subjected to analysis by scanning electron microscopy. for which images are shown in Figure 4.

The representative image (Figure 4a) shows an average diameter of the spheres near $1 \mathrm{~mm}$. The increase in the amplification of 8.000 to 30.000 times (Figure $4 \mathrm{~b}$ and $4 \mathrm{c}$ ) shows a high porosity in the sphere surface. Figure 4d (increase of 104 thousand times), suggests that the porosity observed results from agglomeration of the silica particles used as a precursor, which suggests the platelet shape. This observation, despite the difference in scale, agrees with the porosity observed via $\mathrm{N}_{2}$ adsorption isotherms, which pointed out the presence of pores in the slot shape (Figure 3). The agglomeration or fusion of the particles is due to the action of TEOS used in the precursor mixture, in a process schematically presented in Figure 5.
In the reaction medium which consists of the mixture of chitosan, TEOS and water, TEOS undergoes hydrolysis and then reacts with silanol groups on the silica particle surface (platelet). This process leads to the formation of "bridges" or a link between the platelets, providing mechanical strength for the maintenance of the spherical shape even after calcination to eliminate the organic precursor.

Figure 6 shows a SEM image of $\mathrm{SiO}_{2} @ \mathrm{TiO}_{2}$ spheres and the corresponding elemental mapping of $\mathrm{O}, \mathrm{Si}$ and Ti.

The results of elemental mapping by EDS shows a homogeneous distribution of Ti on the surface of the silica spheres, as suggested by $\mathrm{N}_{2}$ adsorption/desorption isotherms. The presence of Au demonstrated in Figure 6 is related to the gold plating stage reported in the topic of photocatalyst characterization.

\section{X-ray diffraction}

Figure 7 shows the diffractogram of the silica and $\mathrm{SiO}_{2} @ \mathrm{TiO}_{2}$ spheres. Due to the low calcination temperature $\left(550{ }^{\circ} \mathrm{C}\right)$, the profile does not show

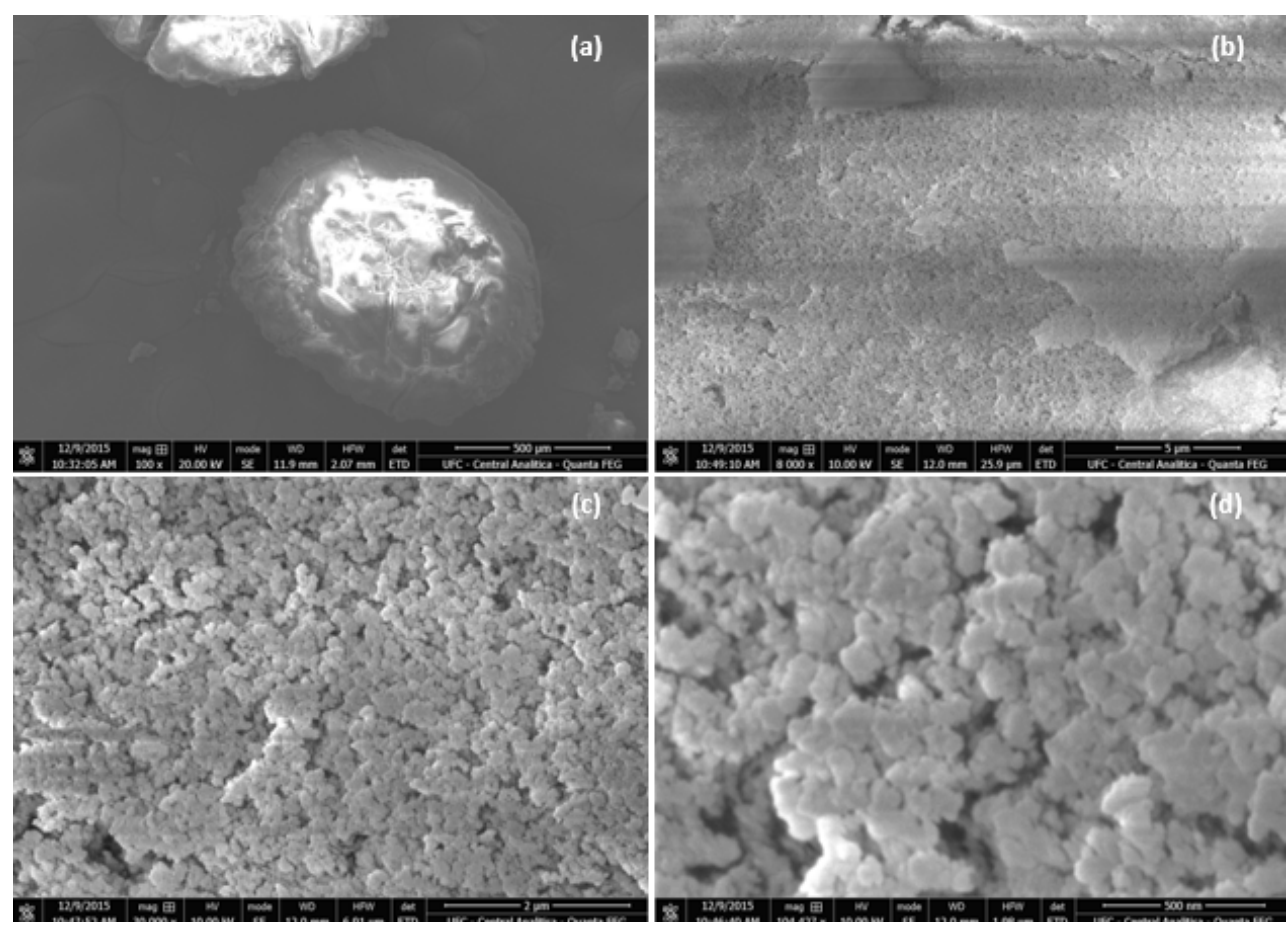

Figure 4. Images of the FEG-SEM of $\mathrm{SiO}_{2} @ \mathrm{TiO}_{2}$ spheres.

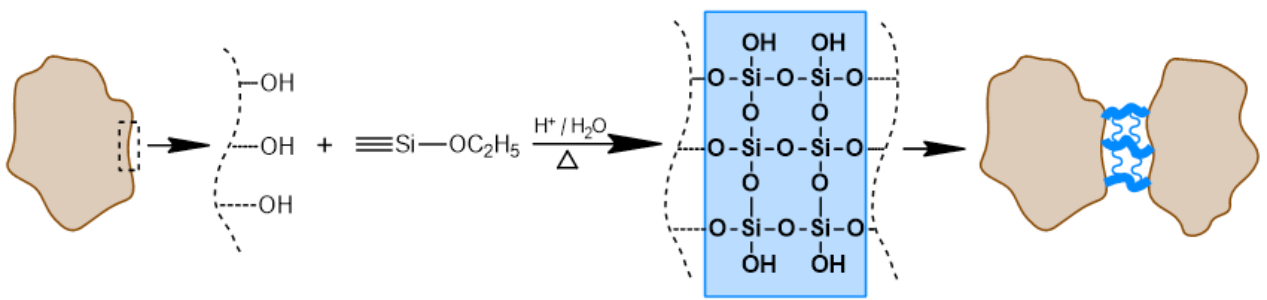

Figure 5. Representative scheme of the fusing process between the silica particles promoted by TEOS, during spheres formation. 

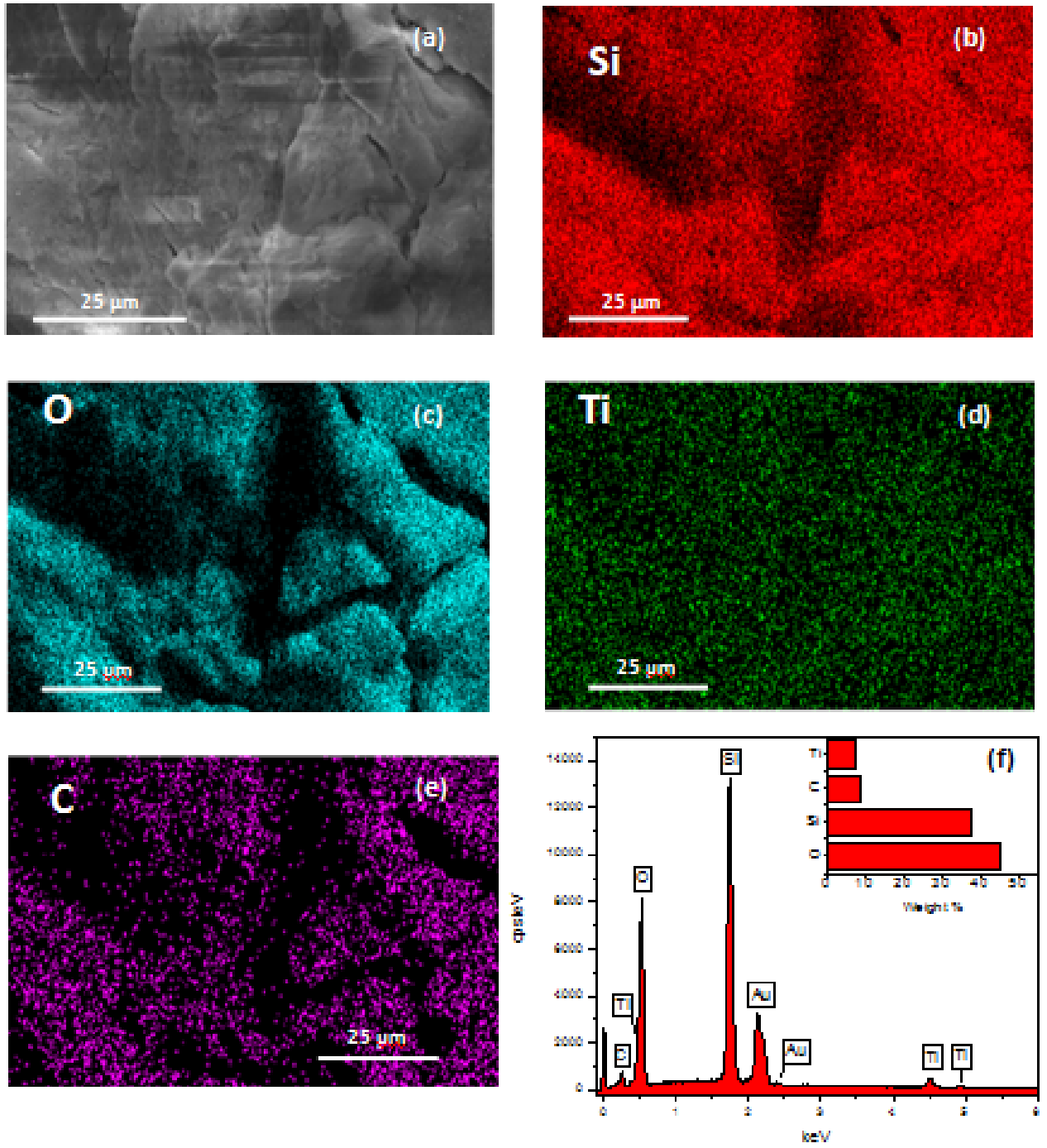

Figure 6. FEG-SEM image (a) and elemental mapping by EDS of $\mathrm{SiO}_{2} @ \mathrm{TiO}_{2}$ spheres (b)-(f).

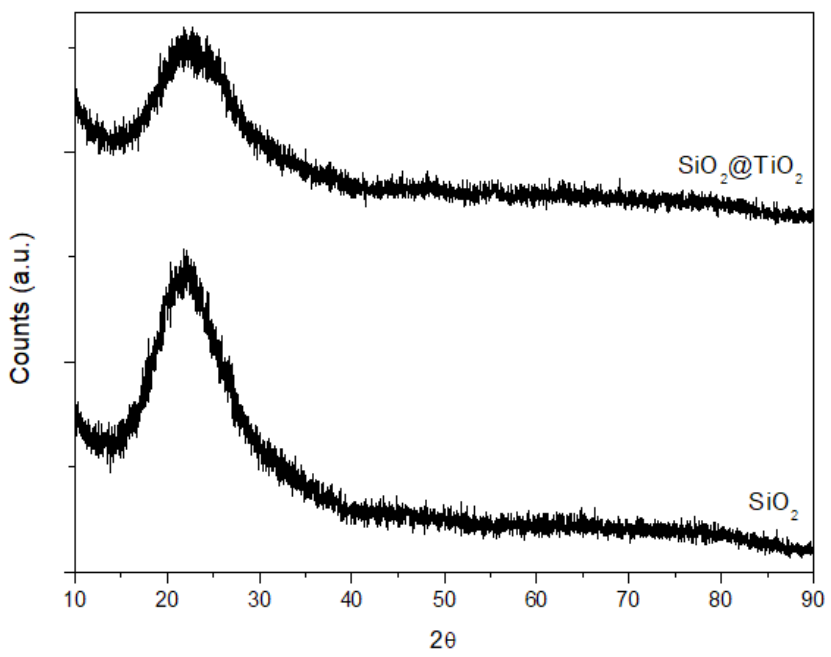

Figure 7. XRD profile of $\mathrm{SiO}_{2}$ and $\mathrm{SiO}_{2} @ \mathrm{TiO}_{2}$ spheres.

diffraction peaks assigned to the crystalline structure of $\mathrm{SiO}_{2}$ phase. However, the high background in the $2 \theta$ range of $15^{\circ}$ to $30^{\circ}$, similar to a wide diffraction peak, is typical of siliceous materials. This fact is attributed to the diffuse dispersion due to the silicon atoms distributed in a disorderly manner in the silicon dioxide lattice (Matos et al., 2011). The impregnation with titanium oxide did not change appreciably the profile of the diffraction pattern of the $\mathrm{SiO}_{2}$ spheres. Nevertheless, it is possible to observe a slight increase of the background at $2 \theta$ degree of $25^{\circ}$.

This small change points to the presence of the anatase phase of $\mathrm{TiO}_{2}$, since the main diffraction peak of the anatase phase is at $2 \theta$ degree of $25^{\circ}$. The low intensity of diffraction peaks of the $\mathrm{TiO}_{2}$ phase may be due to the high dispersion of $\mathrm{TiO}_{2}$, which consequently results in the formation of crystallites with small diameter. Thus, the XRD results are consistent with the data obtained by $\mathrm{N}_{2}$ adsorption/desorption isotherms as well as the image generated by elemental mapping (Figure 6), which indicated the homogeneous $\mathrm{TiO}_{2}$ dispersion.

\section{FT-IR}

The FT-IR spectra of silica and $\mathrm{SiO}_{2} @ \mathrm{TiO}_{2}$ spheres (Figure 8) described similar profiles. An absorption 


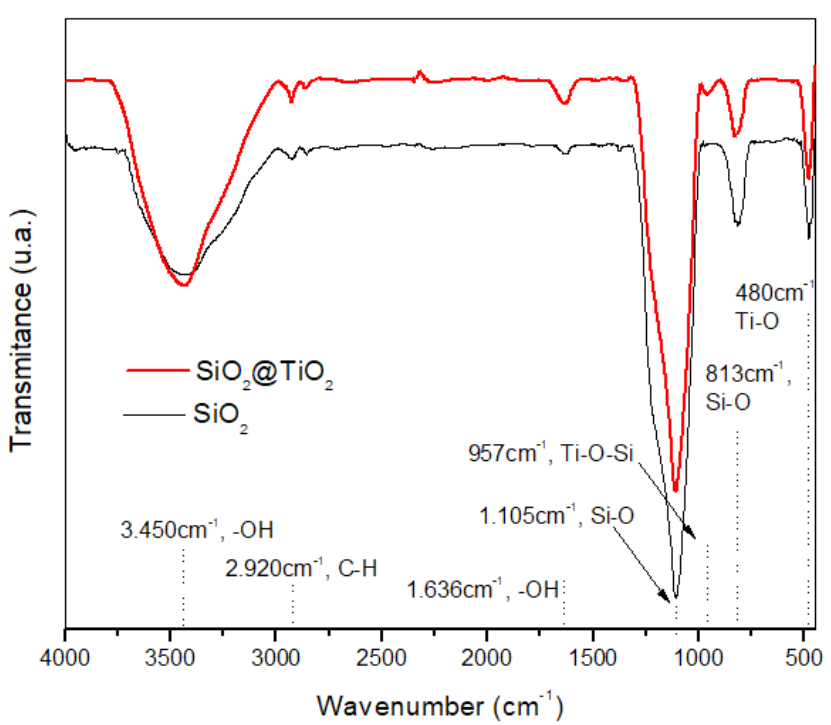

Figure 8. FT-IR spectra of the silica (一) and $\mathrm{SiO}_{2} @$ $\mathrm{TiO}_{2}$ spheres (一).

band located at $3450 \mathrm{~cm}^{-1}$ was identified, which is due to the overlapping of the stretching of $\mathrm{OH}$ groups $(\mathrm{SiOH})$ and the stretching band of adsorbed $\mathrm{H}_{2} \mathrm{O}$. Another absorption band was observed at $1636 \mathrm{~cm}^{2}$ ${ }^{1}$, which is due to the bending of the adsorbed $\mathrm{H}_{2} \mathrm{O}$ molecules (Nagaveni et al., 2004). The absorption peaks observed at 813 and $1105 \mathrm{~cm}^{-1}$ are due to symmetrical and asymmetrical stretching of $\mathrm{Si}-\mathrm{O}-\mathrm{Si}$, respectively. There is a peak at $480 \mathrm{~cm}^{-1}$ that may be due to the bending of Si-O-Si or Ti-O-Ti bonds in the case of $\mathrm{SiO}_{2} @ \mathrm{TiO}_{2}$ spheres. The peak located at 957 $\mathrm{cm}^{-1}$, which appears only in the spectrum of $\mathrm{SiO}_{2} @$ $\mathrm{TiO}_{2}$ spheres, is due to the stretching of Ti-O-Si (Lee et al., 2007; Zhang et al., 2016).

\section{Diffuse Reflectance Spectrum (DRS)}

The diffuse reflectance spectrum of $\mathrm{SiO}_{2} @ \mathrm{TiO}_{2}$ spheres presented in Figure 9 shows the typical profile found for $\mathrm{TiO}_{2}$ in its anatase phase (Serpone et al., 2007; Wang et al., 2007; Llano et al., 2010).

The absorption in the UV region is due to the charge transfer process from the valence band (mainly the $2 \mathrm{p}$ orbital of $\mathrm{O}^{2-}$ ions) to the conduction band $\left(\mathrm{t}_{2 \mathrm{~g}}\right.$ orbitals of $\mathrm{Ti}^{4+}$ ions) (Loddo et al. 1999). The band-gap denotes the energy difference between the valence and conduction bands, in which a higher value is reflected in higher energy to promote the electron quantum jump.

Applying the relationship $[\mathrm{F}(R) \mathrm{hv}]^{2}$ vs. $h v$ it is possible to determine the value of the band-gap, where $\mathrm{F}(R)$ is the Kubelka-Munk function $\left([1-R]^{2} / 2 R\right)$ in relation to the reflectance values, $h$ is Planck's constant and $v$ is the frequency of irradiation. The $\mathrm{x}$-intercept of the graph corresponds to the band-gap value. As inserted in Figure 9, $\mathrm{SiO}_{2} @ \mathrm{TiO}_{2}$ spheres showed a band-gap of $3.30 \mathrm{eV}$, which is close to the one found

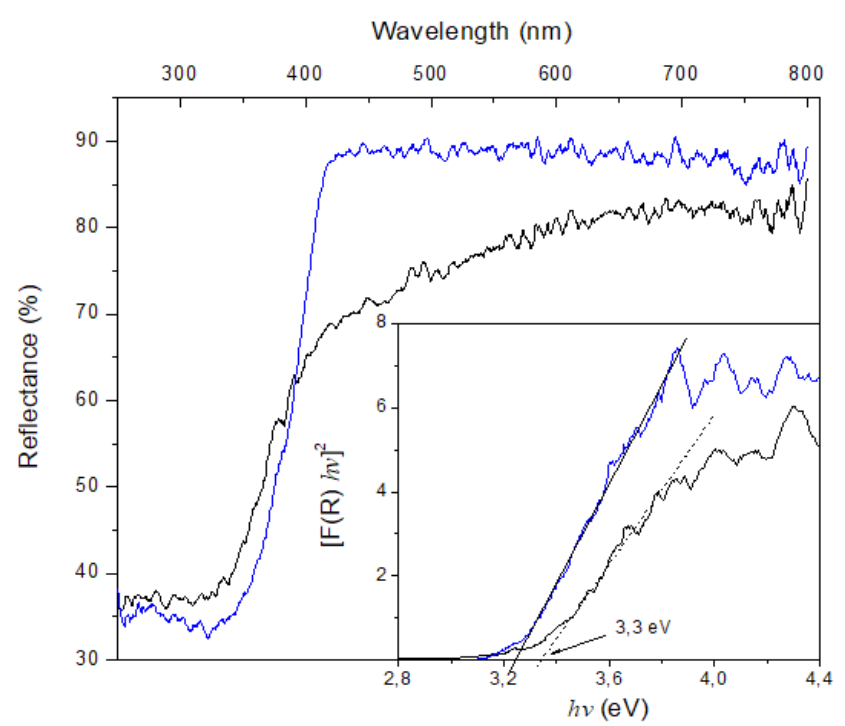

Figure 9. UV-Vis DRS of $\mathrm{TiO}_{2}(-)$ and $\mathrm{SiO}_{2} @ \mathrm{TiO}_{2}$ spheres (-).

in materials composed of titanium in its anatase phase (Jaroenworaluck et al., 2012; Mahesh et al., 2015).

\section{Point of zero charge}

The point of zero charge (PZC) is a property related to the ionization state of the material due to the $\mathrm{pH}$ of the solution. When the $\mathrm{pH}$ of the solution has the same value as the PZC, the material has no charge on its surface. If the $\mathrm{pH}$ is lower than the PZC, the surface material acquires positive charge, as shown in the reactions below:

$\mathrm{TiOH}+\mathrm{H}^{+} \leftrightarrow \mathrm{TiOH}_{2}^{+}$

$\mathrm{SiOH}+\mathrm{H}^{+} \leftrightarrow \mathrm{SiOH}_{2}^{+}$

However, at $\mathrm{pH}$ above $\mathrm{PCZ}$ spheres acquire negative surface charge:

$$
\mathrm{TiOH}+\mathrm{OH}^{-} \leftrightarrow \mathrm{TiO}^{-}
$$

$\mathrm{SiOH}+\mathrm{OH}^{-} \leftrightarrow \mathrm{SiO}^{-}$

The data collected for the PZC determination of synthesized samples are shown in Figure 10. The silica spheres $\left(\mathrm{SiO}_{2}\right)$ present a PZC value of 2.53 , whereas the $\mathrm{SiO}_{2} @ \mathrm{TiO}_{2}$ sample shows a displacement of PCZ to pH value slightly higher (2.90), but still far from the $\mathrm{PZC}$ found for $\mathrm{TiO}_{2}(\mathrm{P} 25)(\mathrm{PZC}=6.41)$. This result is consistent with the elemental mapping by EDS (Figure 6), which points to a high $\mathrm{TiO}_{2}$ dispersion, but shows a predominance of silicon in the composition of the sphere surface.

Therefore, the $\mathrm{pH}$ of the solution for the photocatalytic degradation of MB should be higher 
than 2.9. Since $\mathrm{MB}$ is a cationic dye at $\mathrm{pH}$ lower than $\mathrm{PZC}$, there is an electrostatic inhibition for the $\mathrm{MB}$ adsorption. However, when the medium $\mathrm{pH}$ is higher than PZC, the surface charge is negative.

The surface charge potential data of the samples can be useful to estimate the apparent surface coverage (ASC) of the silica particles by $\mathrm{TiO}_{2}$. ASC \% can be calculated using equation 5 (Lee et al. 2007):

$\% A C S=\frac{\mathrm{M}_{\mathrm{Ti}}\left(\mathrm{PCZ}_{\mathrm{Si}}-\mathrm{PCZ}_{\mathrm{Si}-\mathrm{Ti}}\right)}{\mathrm{M}_{\mathrm{Si}}\left(\mathrm{PCZ}_{\mathrm{Si}-\mathrm{Ti}}-\mathrm{PCZ} \mathrm{Ti}_{\mathrm{Ti}}\right)-\mathrm{M}_{\mathrm{Ti}}\left(\mathrm{PCZ}_{\mathrm{Si}-\mathrm{Ti}}-\mathrm{PCZ}_{\mathrm{Si}}\right)}$

where $M_{T i}$ and $M_{S i}$ are the molecular weights of titania and silica, respectively. The subscript $\mathrm{Si}, \mathrm{Ti}$ and $\mathrm{Si}-\mathrm{Ti}$ refer to samples of silica $\left(\mathrm{SiO}_{2}\right)$, titania $\left(\mathrm{P} 25-\mathrm{TiO}_{2}\right)$ and silica coated with titania $\left(\mathrm{SiO}_{2} @ \mathrm{TiO}_{2}\right)$, respectively. Thus, by making use of Equation 5 it was determined that the $\mathrm{SiO}_{2} @ \mathrm{TiO}$, spheres have 13.2\% coverage. This ratio is relatively low since Lee et al. (2007) reported the synthesis of silica spheres coated with $\mathrm{TiO}_{2}$ that reached ACS values from $90.5 \%$ to $100 \%$ after the first and fifth impregnation, respectively. However, it should be considered that the samples used in this work have a very distinct morphology (Table 1), high surface area and pore volume, $317 \mathrm{~m}^{2} / \mathrm{g}$ and 2.402 $\mathrm{cm}^{3} / \mathrm{g}$, respectively.

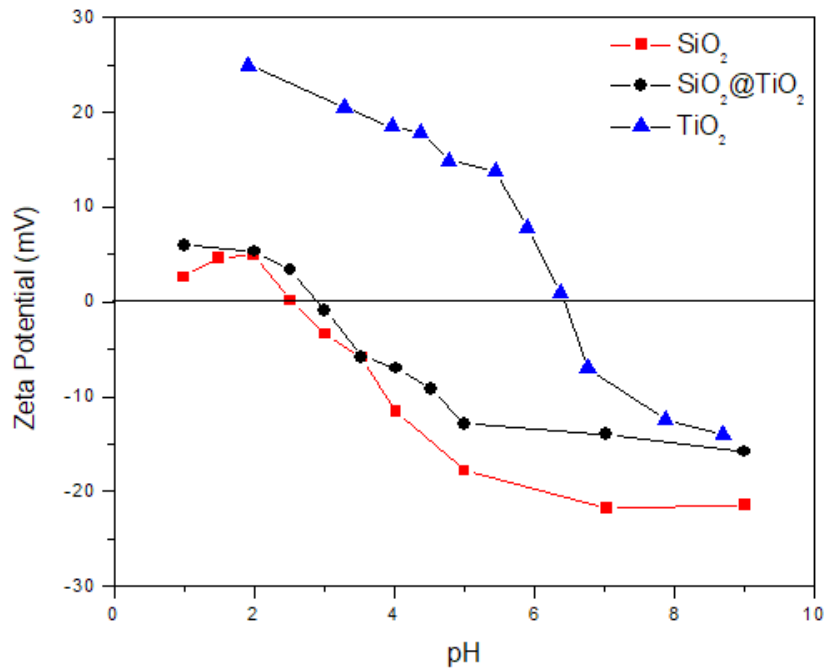

Figure 10. Point of Zero Charge (PZC) of $\mathrm{SiO}_{2}$ e $\mathrm{SiO}_{2} @ \mathrm{TiO}_{2}$ spheres and $\mathrm{TiO}_{2}$.

\section{Photocatalytic activity}

The tests to confirm the photocatalytic activity of the synthesized spheres were performed in MB solution $\left(\mathrm{C}_{0}\right.$ $=5.0 \mathrm{mg} / \mathrm{L}$ ) at a dosage of $0.5 \mathrm{~g} / \mathrm{L}$ of the photocatalyst for a period of 6 hours of irradiation under constant aeration. In parallel, an experiment was carried out in the absence of light to evaluate the adsorption kinetics and the net effect of the photocatalytic process. Additionally, an experiment was conducted to better visualize the photocatalytic step where the spheres remained in contact with the dye for 6 hours in the absence of light, and thereafter the lamp was operated for 2 hours. Figure 11 shows the color reduction data of the aqueous solution of MB under the action of the $\mathrm{SiO}_{2} @ \mathrm{TiO}_{2}$ spheres with and without the presence of light, in addition to the net effect of the photocatalysis after adsorption equilibrium (inserted).

The kinetic profiles of MB discoloration by the action of the $\mathrm{SiO}_{2} @ \mathrm{TiO}_{2}$ spheres with and without irradiation were similar in the initial times, with a slightly higher reaction rate in the test with the presence of light. After 60 minutes of reaction a greater distance of the kinetic curves that represent the reduction of concentration of the dye is perceived. This fact is more evident in the final times of the experiment, where it is observed that the system tends to adsorption equilibrium in the absence of light, whereas with the presence of UV-C irradiation the rate of discoloration decreased.

Another confirmation of the photocatalytic activity of the $\mathrm{SiO}_{2} @ \mathrm{TiO}_{2}$ spheres is given by the variation of the kinetic profile of the reduction of the methylene blue concentration observed in the inserted figure. In this case, the first 6 hours were destined to reach the adsorption equilibrium, where a different kinetic profile was visualized from the previous one when the lamp was started, and the photocatalytic stage was started. The higher efficiency of reducing the concentration of dye observed in the experiment with presence of irradiation is related to the excitation of the fraction of titania exposed to light, allowing reactive species, such as the hydroxyl radical, to be produced on the surface of the material, promoting the degradation of the adsorbed organic molecules and releasing the irradiated sites so that new methylene blue molecules are adsorbed.

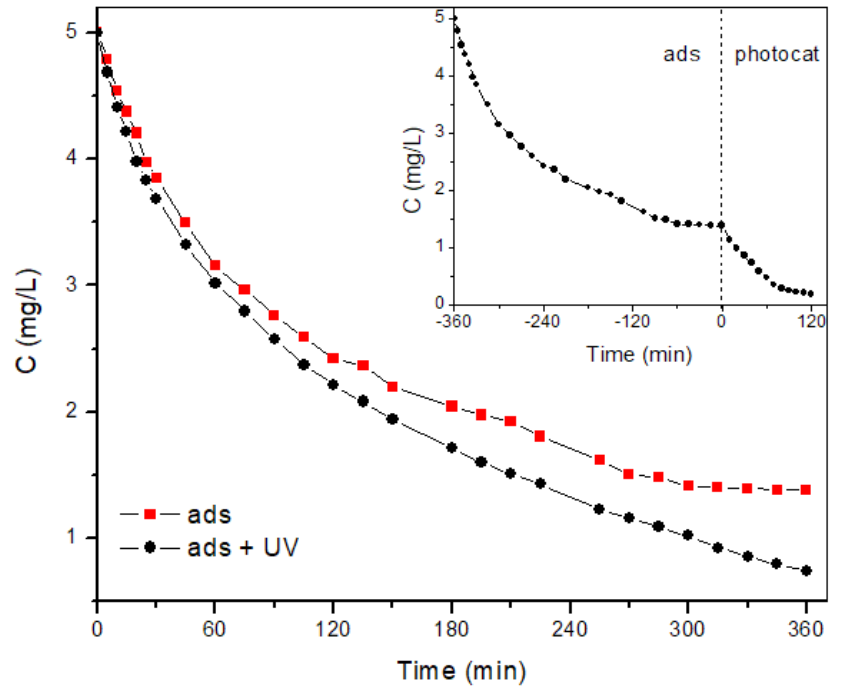

Figure 11. Photocatalytic activity of the $\mathrm{SiO}_{2} @ \mathrm{TiO}_{2}$ spheres on photodegradation of methylene blue. [MB $]_{0}^{2}$ $=5.0 \mathrm{mg} / \mathrm{L}, \mathrm{SiO}_{2} @ \mathrm{TiO}_{2}=0.5 \mathrm{~g} / \mathrm{L}, \mathrm{pH}=5.6, \mathrm{~T}=20$ ${ }^{\circ} \mathrm{C}$. 


\section{Effect of initial concentration of methylene blue}

The analysis of the initial concentration effect of methylene blue on photodegradation kinetics in heterogeneous catalytic processes is commonly performed by applying the Langmuir-Hinshelwood model (L-H) (Ollis, 2005; Serpone et al., 2007). The application of this model in reactors operated in batch mode is given by expression 6, which its integrated form is shown in equation 7 (Asenjo et al., 2013).

$$
\mathrm{r}=-\frac{\mathrm{dC}}{\mathrm{dt}}=\frac{\mathrm{k}_{\mathrm{r}} \mathrm{K}_{\mathrm{S}}^{*} \mathrm{C}}{1+\mathrm{K}_{\mathrm{S}}^{*} \mathrm{C}}
$$

$$
\frac{\mathrm{C}}{\exp \left[\mathrm{K}_{\mathrm{S}}^{*}\left(\mathrm{C}_{0}-\mathrm{C}\right)\right]}=\mathrm{C}_{0} \exp \left(-\mathrm{k}_{\mathrm{r}} \mathrm{K}_{\mathrm{S}}^{*} \mathrm{t}\right)
$$

where $C_{0}$ and $C$ are the initial and residual substrate concentrations, respectively $(\mathrm{mg} / \mathrm{L}), k_{r}$ is the apparent rate constant $\left(\mathrm{min}^{-1}\right)$ and $K_{S}{ }^{*}$ is a pseudo-equilibrium constant related to monolayer adsorption $(\mathrm{L} / \mathrm{mg})(\mathrm{Xu}$ et al., 2007). The calculation of the constant $(k)$ must be performed by iterative procedures, since it is not possible to isolate $C$ from equation 7 . Therefore, the Solver tool (Excel, Microsoft ${ }^{\circledR}$ ) was employed in order to minimize the error between the two terms of equation 7, setting the value of $K_{S}^{*}$.

The application of the Langmuir-Hinshelwood (L-H) kinetic model assumes a non-competitive adsorption between the intermediate and the initial substrate (Xu et al. 2007). However, considering the fact that the sample is not in the form of finely divided powder, but in the spherical shape, the photocatalytic process possibly occurs on the exposed surface sites most susceptible to excitation by incident irradiation. Thus, an isotherm adsorption of MB was performed with $\mathrm{SiO}_{2} @ \mathrm{TiO}_{2}$ spheres previously saturated with MB to estimate the value of $K_{S}^{*}$ corresponding to the surface layer of the sphere sites. The $K_{S}{ }^{*}$ value was obtained by isotherm adsorption disregarding the apparent dependence of the adsorption constant $\left(K_{S}^{*}\right)$ with irradiation, since the surface properties of a photocatalytic material are influenced dramatically when excited (Xu and Langford, 2000). Therefore, the spheres were kept in contact with the dye solution (5.0 $\mathrm{mg} / \mathrm{L}$ ) for 24 hours to reach adsorption equilibrium. Afterwards, the spheres were transferred to a beaker containing $100 \mathrm{ml}$ of deionized water and the system was then UV-C irradiated for 2 hours. Posteriorly the spheres were dried at $105{ }^{\circ} \mathrm{C}$ and the adsorption isotherm was carried out again. Under this condition, the maximum adsorption capacity $\left(q_{\max }\right)$ was 2.936 $\mathrm{mg} / \mathrm{g}$ and the adsorption constant $\left(K_{S}^{*}\right)$ was $0.560 \mathrm{~L} /$ $\mathrm{mg}$ obtained by the Langmuir model. These values are related to the adsorption of $\mathrm{MB}$ on sites located on the surface of the spheres, which are active in the photocatalytic process due to their continuous exposure to the radiation, unlike the innermost sites that were saturated with the dye and remain occluded to the radiation .

These assays that show the effect of initial concentration of dye on the photocatalytic performance of the spheres (Figure 12) were done after reaching the adsorption equilibrium without irradiation source. Figure 12 also shows the fitting of the L-H model (equation 7) applied to experimental data.

As shown in Table 2, the initial concentration of dye affects the initial rate of photocatalytic degradation of methylene blue by $\mathrm{SiO}_{2} @ \mathrm{TiO}_{2}$ spheres. This relationship follows the rate reaction law, where an increase in the concentration of reacting species increases the reaction rate.

However, this increment becomes less significant in the range of higher initial concentrations, which should be due to the decrease in transmittance of the aqueous solution with increasing dye concentration. If the intensity of the irradiation incident is constant, a smaller number of photons reach the surface of the photocatalyst with the increment of dye concentration. Consequently, the photocatalytic mechanism that is given by the photonic excitation of the semiconductor, i.e., the titania impregnated in the $\mathrm{SiO}_{2}$, is affected.

Another feature which should be further studied is the suggestion in the profiles in Figure 12 of changes

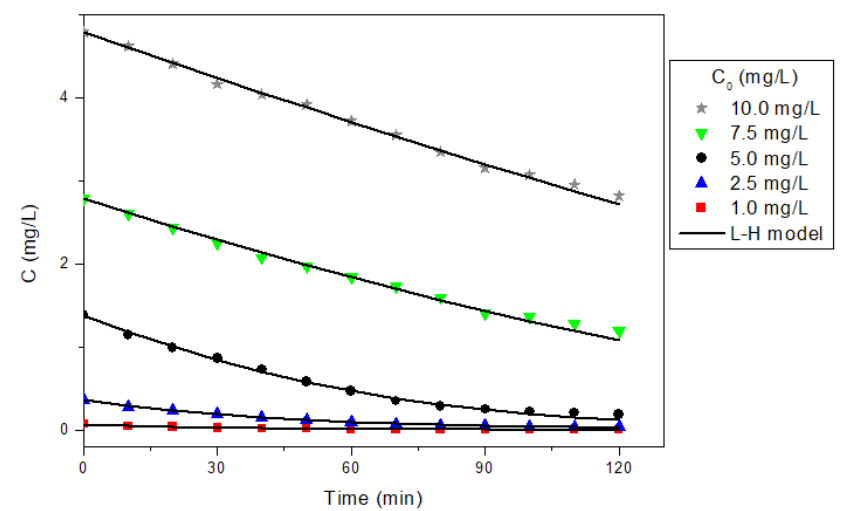

Figure 12. Effect of the initial concentration of methylene blue on the photocatalytic degradation. $\mathrm{SiO}_{2} @ \mathrm{TiO}_{2}=0.5 \mathrm{~g} / \mathrm{L}, \mathrm{pH}=5.6, \mathrm{~T}=20^{\circ} \mathrm{C}$.

Table 2. Kinetic data of the L-H model in the photocatalytic degradation of methylene blue by $\mathrm{SiO}_{2} @ \mathrm{TiO}_{2}$ spheres. Catalyst $=0.5 \mathrm{~g} / \mathrm{L}, \mathrm{pH}=5.6, \mathrm{~T}$ $=20^{\circ} \mathrm{C}$.

\begin{tabular}{cccc}
\hline $\boldsymbol{C}_{\boldsymbol{0}}{ }^{*}(\mathrm{mg} / \mathrm{L})$ & $\boldsymbol{k}_{\boldsymbol{r}}\left(\mathrm{min}^{-1}\right)$ & $\boldsymbol{r}_{\boldsymbol{0}}(\mathbf{m g} / \mathbf{L . m i n})$ & $\mathbf{R}$ \\
\hline 0.07 & 0.0604 & 0.0023 & 0.9962 \\
0.36 & 0.0432 & 0.0094 & 0.9988 \\
1.38 & 0.0369 & 0.0161 & 0.9973 \\
2.78 & 0.0282 & 0.0171 & 0.9979 \\
4.79 & 0.0257 & 0.0187 & 0.9979 \\
\hline
\end{tabular}

"after adsorption equilibrium. $K_{S}^{*}=0.560 \mathrm{~L} / \mathrm{mg} . r_{0}=$ initial degradation rate. 
of the reaction order due to differences of the initial concentration of the dye. Considering equation 6 this possible regime change may be due to two extreme cases: firstly for high concentrations of methylene blue, the adsorption kinetics are fast enough to consider $K_{S}{ }^{*} C>>1$. Therefore, equation 6 takes the form of the rate law of zero-order, according to equation 8 , as suggested by the tests in which initial concentrations of 2.78 and $4.79 \mathrm{mg} / \mathrm{L}$ were applied. However, $k_{a}$ (apparent rate constant) is not necessarily equal to $k_{r}$.

$-\frac{\mathrm{dC}}{\mathrm{dt}}=\mathrm{k}_{\mathrm{a}}$

The second case is for a low dye concentration with a higher effect from the adsorption step. In such conditions $K_{S}^{*} C<<1$ is changing the process to reaction of pseudo-first order (equation 9), as suggested by data from tests performed with initial concentrations of $0.07,0.36$ and $1.38 \mathrm{mg} / \mathrm{L}$.

$-\frac{\mathrm{dC}}{\mathrm{dt}}=\mathrm{k}_{\mathrm{ap}} \mathrm{C}$

where $k_{a p}=k_{r} K_{S}^{*}$.

This clear effect of the initial concentration in the profiles shown in Figure 12 confirms that the $K_{S}$ calculated considering the adsorption sites present on the more exposed layers of the sphere is consistent. In addition, for the experimental conditions selected ( $K_{S}$ value and concentration range) the LangmuirHinshelwood model fitted well to the data with a correlation factor $(\mathrm{R})$ greater than 0.99 for all concentrations tested.

\section{Reuse of photocatalyst}

The potential reuse of the material is an important parameter to verify the practical application as a photocatalyst, since it contributes to the reduction of the operational costs. In this study, after the adsorption of MB on the $\mathrm{SiO}_{2} @ \mathrm{TiO}_{2}$ sphere surface, the sample was subjected to photocatalytic test under UV-C irradiation for 2 hours (1st cycle). At the end of the irradiation time the spheres were transferred from the dye aqueous matrix to $200 \mathrm{~mL}$ of deionized water and the system was subjected to UV-C irradiation for 2 hours. After drying at $105^{\circ} \mathrm{C}$ for 12 hours, the sample was subjected to a new operating cycle (2nd cycle). The results corresponding to operating cycles of reuse are shown in Figure 13.

The results presented in Figure 13 suggest a good stability of the photocatalyst, despite the small decrease in the reaction kinetics due to the reuse. The data also point out that the proposed method of regenerating the photocatalytic spheres proved to be effective. This fact

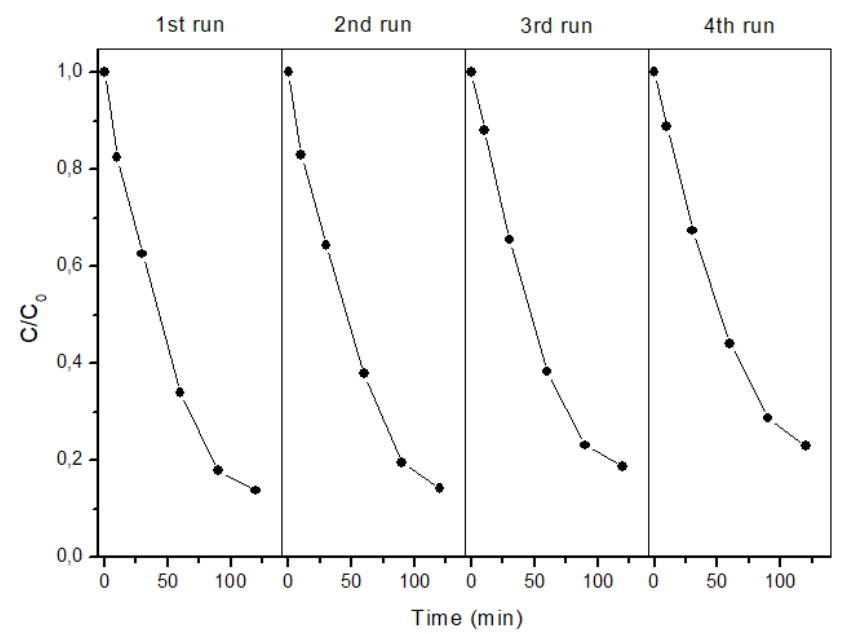

Figure 13. Reuse of $\mathrm{SiO}_{2} @ \mathrm{TiO}_{2}$ spheres regenerated by UV-C irradiation. $\mathrm{pH}=5.6, \mathrm{~T}=20^{\circ} \mathrm{C}, \mathrm{SiO}_{2} @ \mathrm{TiO}_{2}$ $=0.5 \mathrm{~g} / \mathrm{L}, \mathrm{C}_{0}=1.7 \mathrm{mg} / \mathrm{L}$.

can be explained by taking into account that only sites present on the outermost surface of the spheres are exposed to irradiation, i.e., $\mathrm{TiO}_{2}$ when excited promote the degradation of methylene blue adsorbed on the surface, while the inner portion is occluded within the porous matrix, hindering the excitation of titania in this region.

The SEM of the sample $\mathrm{SiO}_{2} @ \mathrm{TiO}_{2}$ with elemental mapping was recorded posteriorly to the regeneration process, for which images are shown in Figure 14.

Similarly to the image recorded before the catalytic test (Figure 6), it can be seen that Ti is uniformly dispersed on the sphere surface. The presence of carbon and nitrogen is also observed, which may be from the molecular structure of the dye, but the carbon content is similar to the one determined for the measurement sample performed before the photocatalytic activity test (Figure 6).

By comparing the results from EDS (Figures 6 and 14), a decrease of the $\mathrm{Si} / \mathrm{C}$ ratio from 4.2 to 2.1 is observed for the samples before and after the catalytic test, respectively. This may be due to the absence of photocatalytic activity of the silica fraction, which is not regenerated by UV-C irradiation, unlike the titania fraction.

\section{Additives effect}

It is known that both the radicals and the holes photo-generated in the semiconductor can promote the degradation of organic substances (Houas et al., 2001; Park et al., 2013). For a better understanding of the photocatalytic mechanism acting in the system under study, methylene blue degradation experiments were performed using sequestering agents of radicals and holes. Figure 15 shows the results obtained in the photocatalytic performance test of $\mathrm{SiO}_{2} @ \mathrm{TiO}_{2}$ spheres in the presence of different additives (radical scavengers), for which effects are evident. In a similar 

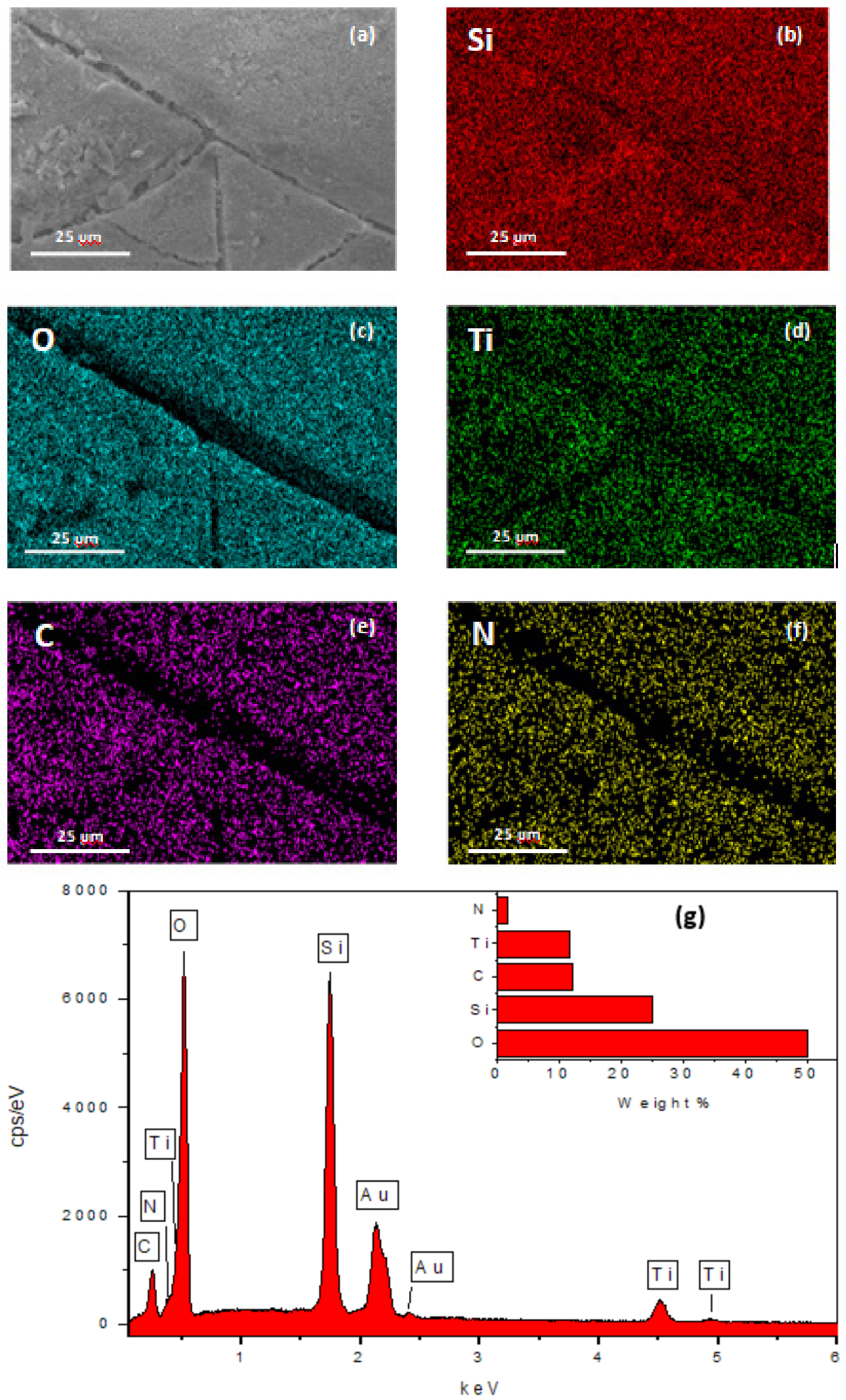

Figure 14. SEM Image (a) and elemental mapping by EDS of $\mathrm{SiO}_{2} @ \mathrm{TiO}_{2}$ spheres (b-g) after UV-C irradiation regeneration.

way to the previous catalytic tests, these experiments were also performed after the equilibrium adsorption, in the absence of light, between the dye and the additive with the spheres.
Under airflow and without additive, the photocatalytic degradation of MB (Fig. 15) observed was $86 \%$ after $120 \mathrm{~min}$. The addition of t-butyl alcohol (TBA, $1.0 \mathrm{mM}$ ), which is considered as an excellent 
scavenger of hydroxyl radicals ( $\left.{ }^{\circ} \mathrm{OH}\right)$ (Li et al., 2010; Zheng et al., 2014), significantly suppressed the photocatalytic activity of the spheres. Considering that, in the presence of TBA, the degradation of MB is only $4 \%$ after $30 \mathrm{~min}$, whereas the test conducted in the absence of scavenger, a MB degradation of $48 \%$ in the same time interval is observed, this result suggests that the degradation process is promoted mainly by the 'OH radical. However, it is known that in the presence of $\mathrm{O}_{2}$ the formation of superoxide radical $\left(\mathrm{O}_{2}^{-\cdot}\right)$ occurs. Thus, the test was conducted using benzoquinone (BQ), since it has the ability to scavenge $\mathrm{O}_{2}^{-{ }^{-}}$by an electron transfer mechanism (Yang et al., 2005; Gao and Wang, 2013). The addition of BQ $(1.0 \mathrm{mM})$ also resulted in a decrease of the spheres' activity, but this decrease is less intense than the one observed for TBA. In the test with BQ it should be considered that this agent has a maximum absorbance band at $245 \mathrm{~nm}$, and this may affect the intensity of radiation that reached the material and, as a result, there may actually be observed a higher effect than just the capture of $\mathrm{O}_{2} \cdot$ radical.

On the other hand, the photocatalytic assays were carried out in the presence of oxygen, with constant injection of atmospheric air in the reaction system. The $\mathrm{O}_{2}$ acts as a source of $\mathrm{O}_{2}^{-*}$ and also keeps the photogenerated pair $e_{c b}{ }^{-1 / h_{v b}}{ }^{+}$separated, favouring the photocatalytic mechanism. In order to evaluate the influence of $\mathrm{O}_{2}$ on the photocatalytic process, $\mathrm{N}_{2}$ was used instead. $\mathrm{N}_{2}$ was bubbled through the dye solution for one hour prior to starting the irradiation, and continuously injected throughout the reaction time. The results presented in Figure 15 do not allow us to state that all $\mathrm{O}_{2}$ initially dissolved in solution was eliminated by bubbling $\mathrm{N}_{2}$, but the data confirm the contribution of the $\mathrm{O}_{2}^{-{ }^{-}}$radical in the $\mathrm{MB}$ degradation process.

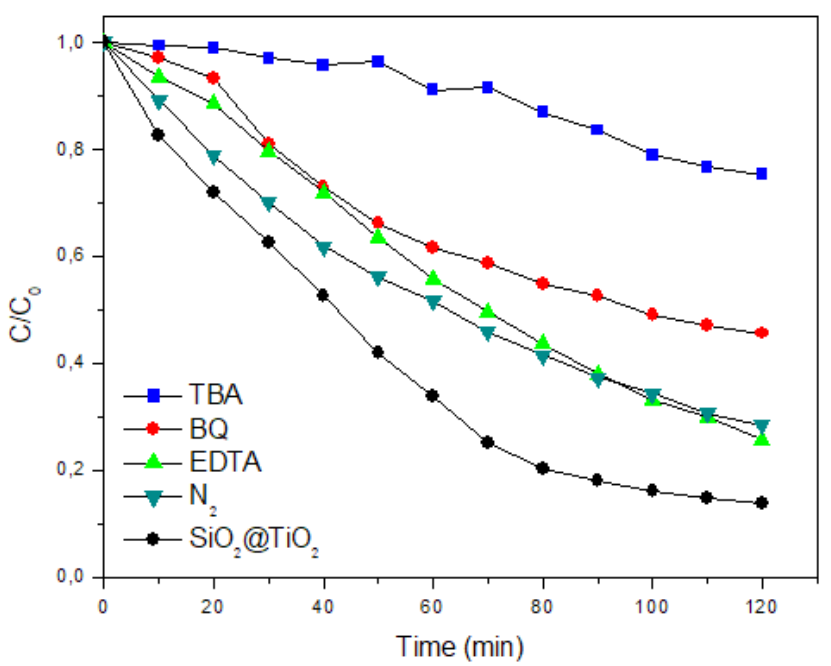

Figure 15. Effect of various additives on the photocatalytic degradation of methylene blue by $\mathrm{SiO}_{2} @ \mathrm{TiO}_{2}$ spheres.
The photogenerated holes also play an important role in the photocatalytic mechanism, acting in the direct oxidation of the species adsorbed on the surface, without intermediation of radicals. This process can be verified by the hole being captured by ethylenediaminetetraacetic acid (EDTA) (Xin et al., 2011).

The use of EDTA $(1.0 \mathrm{mM})$ as hole scavenger decreased the rate of MB degradation. However, the effect of EDTA is less meaningful than the one promoted by TBA and BQ. It should be noted that the suppression of degradation activity was more pronounced in the first minutes of reaction for all additives used. This suggests that the concentration of the additive dropped to values at which their efficiency is less pronounced. However the objectives have been achieved, which was the confirmation that the photocatalytic degradation mechanism occurs through direct $\left(h_{v b}{ }^{+}\right)$or indirect $\left({ }^{\circ} \mathrm{OH}\right)$ oxidation reactions, as shown in the reactions below (Houas et al., 2001):

Excitation of photocatalyst:

$$
\mathrm{TiO}_{2} \stackrel{\mathrm{hv}}{\rightarrow} \mathrm{e}_{\mathrm{CB}}^{-}+\mathrm{h}_{\mathrm{vB}}^{+}
$$

Direct oxidation:

$\mathrm{h}_{\mathrm{VB}}^{+}+\mathrm{R} \rightarrow \mathrm{R}^{+}$

Indirect oxidation:

$\left(\mathrm{H}_{2} \mathrm{O} \leftrightarrow \mathrm{H}^{+}+\mathrm{OH}^{-}\right)_{\text {ads }}+\mathrm{h}_{\mathrm{VB}}^{+} \rightarrow \mathrm{H}^{+}+\mathrm{OH}^{\cdot}$

$\left(\mathrm{O}_{2}\right)_{\mathrm{ads}}+\mathrm{e}_{\mathrm{CB}}^{-} \rightarrow \mathrm{O}_{2}^{-}$

$\mathrm{O}_{2}^{--}+\mathrm{H}^{+} \rightarrow \mathrm{HO}_{2}^{-}$

$2 \mathrm{HO}_{2} \rightarrow \mathrm{H}_{2} \mathrm{O}_{2}+\mathrm{O}_{2}$

$$
\mathrm{H}_{2} \mathrm{O}_{2}+\mathrm{e}_{\mathrm{CB}}^{-} \rightarrow \mathrm{OH}^{-}+\mathrm{OH}^{-}
$$

$$
\mathrm{R}+\mathrm{OH}^{\cdot} \rightarrow \mathrm{R}^{\prime}+\mathrm{H}_{2} \mathrm{O}
$$

The results presented in Figure 15 point out that the predominant mechanism in the photocatalytic degradation of methylene blue by $\mathrm{SiO}_{2} @ \mathrm{TiO}_{2}$ spheres is via indirect oxidation reactions. Specifically the oxidation is promoted by the ${ }^{\circ} \mathrm{OH}$ radical, which is produced from water adsorbed on the catalyst surface (equation 12) and via the reduction of $\mathrm{O}_{2}$ (equations 13-16). 


\section{Benzene hydroxylation}

Figure 16 shows the evolution of data for the photocatalytic hydroxylation reaction of benzene by $\mathrm{SiO}_{2} @ \mathrm{TiO}$, spheres. The photocatalytic performance showed $7.2 \%$ of benzene converted at the end of the reaction time of 240 minutes, and $56 \%$ of selectivity to phenol. The isolated application of UV-Irradiation on benzene in aqueous media did not lead to its hydroxylation.

The main problem or difficulty of this process is the consecutive reactions, which lead to hydroquinone (HQ) and benzoquinone (BQ) production, as shown in Figure 17. The experimental conditions applied here for the photocatalytic hydroxylation of benzene by the $\mathrm{SiO}_{2} @ \mathrm{TiO}_{2}$ spheres do not provide detectable production of catechol (CT), suggesting that the route of addition of hydroxyl groups to benzene takes place preferably in the para position (Figure 16). The concentration of $\mathrm{BQ}$ reached an appreciable value relative to the HQ concentration at the end of the reaction time of 240 minutes. However, considering the first 60 minutes of reaction, HQ concentration is higher than BQ. This profile suggests the occurrence of consecutive reaction. The oxidative conditions of the system lead to the conversion of HQ to BQ, but the equilibrium reaction between these two species in the aqueous system cannot be ruled out.

On the other hand, it is reasonable to accept that the production of BQ may occur from phenol without $\mathrm{HQ}$ desorption, since the ${ }^{\circ} \mathrm{OH}$ radical is highly reactive. Based on these remarks, Figure 17 shows a reaction scheme for conversion of benzene to phenol and its derivatives.

Considering the values of monitored concentration for the species shown in Figure 16 and taking into account the reaction scheme proposed in Figure 17,

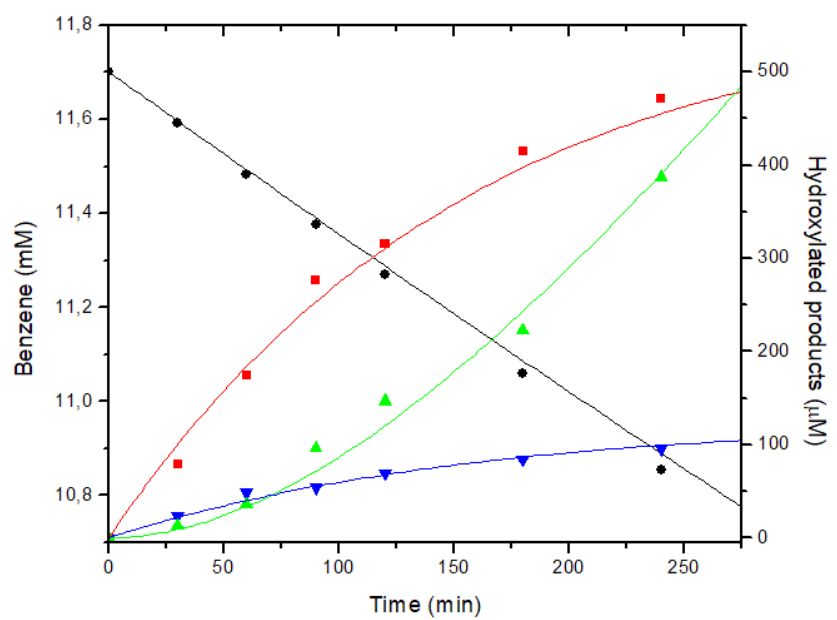

Figure 16. Kinetics of photocatalytic hydroxylation of benzene $(\bullet)$ to phenol $(\boldsymbol{\bullet})$, hydroquinone $(\boldsymbol{\nabla})$ and benzoquinone $(\mathbf{\Delta})$. $[\mathrm{Bz}]_{0}=11.7 \mathrm{mM}$, solvent $=$ water $(70 \mathrm{~mL})+$ acetonitrile $(5 \mathrm{~mL})$, Lamp: UV-A $(5 \mathrm{~W})$, $\mathrm{SiO}_{2} @ \mathrm{TiO}_{2}: 0.75 \mathrm{~g}$.

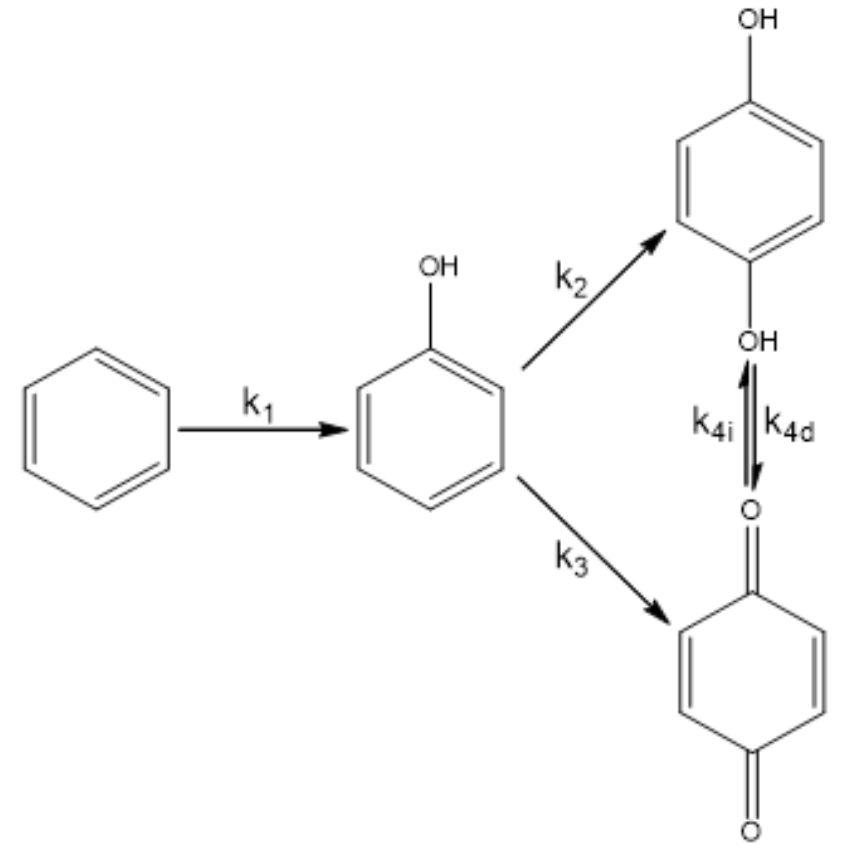

Figure 17. Reaction scheme for the photocatalytic conversion of benzene to phenol and its derivatives.

a kinetic model for the photocatalytic hydroxylation of benzene is proposed, however, without considering the adsorption and desorption steps of each product. The rate laws for first-order of each species are given below:

$-\frac{\mathrm{dC}_{\mathrm{Bz}}}{\mathrm{dt}}=\mathrm{k}_{1} \mathrm{C}_{\mathrm{Bz}}$

$\frac{\mathrm{dC}_{\mathrm{PhOH}}}{\mathrm{dt}}=\mathrm{k}_{1} \mathrm{C}_{\mathrm{Bz}}-\mathrm{k}_{2} \mathrm{C}_{\mathrm{PhOH}}-\mathrm{k}_{3} \mathrm{C}_{\mathrm{PhOH}}$

$\frac{\mathrm{dC}_{\mathrm{HQ}}}{\mathrm{dt}}=\mathrm{k}_{2} \mathrm{C}_{\mathrm{PhOH}}+\mathrm{k}_{4 \mathrm{i}} \mathrm{C}_{\mathrm{BQ}}-\mathrm{k}_{4 \mathrm{~d}} \mathrm{C}_{\mathrm{HQ}}$

$\frac{\mathrm{dC}_{\mathrm{BQ}}}{\mathrm{dt}}=\mathrm{k}_{3} \mathrm{C}_{\mathrm{PhOH}}+\mathrm{k}_{4 \mathrm{~d}} \mathrm{C}_{\mathrm{HQ}}-\mathrm{k}_{4 \mathrm{i}} \mathrm{C}_{\mathrm{BQ}}$

Based on the little change observed for the hydroquinone concentration with the reaction time, equations 18-21 can be solved by applying the steady state approach to $\mathrm{HQ}$, according to the following equations:

$\mathrm{C}_{\mathrm{Bz}}=\mathrm{C}_{\mathrm{Bz}_{0}} \mathrm{e}^{-\mathrm{k}_{1} \mathrm{t}}$

$\mathrm{C}_{\mathrm{PhOH}}=\mathrm{C}_{\mathrm{Bz}_{0}}\left(\frac{\mathrm{k}_{1}}{\mathrm{k}_{2}+\mathrm{k}_{3}-\mathrm{k}_{1}}\right)\left(\mathrm{e}^{\left(-\mathrm{k}_{1} \mathrm{t}\right)}-\mathrm{e}^{-\left(\mathrm{k}_{2}+\mathrm{k}_{3}\right) \mathrm{t}}\right)$ 


$$
\begin{gathered}
\mathrm{C}_{\mathrm{HQ}}=\frac{\mathrm{C}_{\mathrm{Bz}_{0}}}{\mathrm{k}_{4 \mathrm{~d}}}\left[\frac{\mathrm{k}_{1} \mathrm{k}_{2}\left(\mathrm{e}^{-\mathrm{k}_{1} \mathrm{t}}-\mathrm{e}^{-\left(\mathrm{k}_{2}+\mathrm{k}_{3}\right) \mathrm{t}}\right)+\mathrm{k}_{4 \mathrm{i}}\left(\mathrm{k}_{1} \mathrm{e}^{-\left(\mathrm{k}_{2}+\mathrm{k}_{3}\right) \mathrm{t}}-\left(\mathrm{k}_{2}+\mathrm{k}_{3}\right) \mathrm{e}^{-\mathrm{k}_{\mathrm{t}} \mathrm{t}}\right)}{\mathrm{k}_{2}+\mathrm{k}_{3}-\mathrm{k}_{1}}+\mathrm{k}_{4 \mathrm{i}}\right] \\
\mathrm{C}_{\mathrm{BQ}}=\mathrm{C}_{\mathrm{Bz}_{0}}\left(\frac{\mathrm{k}_{1} \mathrm{e}^{-\left(\mathrm{k}_{2}+\mathrm{k}_{3}\right) \mathrm{t}}-\left(\mathrm{k}_{2}+\mathrm{k}_{3}\right) \mathrm{e}^{-\mathrm{k}_{1} \mathrm{t}}}{\mathrm{k}_{2}+\mathrm{k}_{3}-\mathrm{k}_{1}}+1\right)
\end{gathered}
$$

Table 3 shows the kinetic constants calculated by applying equations $21-25$ to the experimental data of benzene photocatalytic hydroxylation. The values of the kinetic constants suggest that the secondary route of photocatalytic conversion of benzene, i.e., formation of phenolic intermediates, occurs preferably towards the production of HQ, $k_{2}$ being higher than $k_{3}$. The $k_{2}$ to $k_{3}$ ratio of 1.50 is consistent with the higher HQ concentration, compared to BQ, in the first hour. However, due to the equilibrium reaction between $\mathrm{HQ}$ and $\mathrm{BQ}$, the values of the kinetic constants related to the $\mathrm{HQ} / \mathrm{BQ}$ balance point to a BQ predominance $\left(k_{4 d}\right.$ $>k_{4 i}$ ) with $\mathrm{BQ}$ production being favoured. These observations are consistent with the data presented in Figure 16, which show higher concentration of benzoquinone instead of hydroquinone after $60 \mathrm{~min}$ of reaction time.

Since $k_{2} / k_{1}$ and $k_{3} / k_{1}$ ratios are 10.5 and 7.0, respectively, it is suggested that the concentration of $\mathrm{PhOH}$ will reach the steady state. The experimental data (Figure 16) matche with this observation; the curve points out that $\mathrm{PhOH}$ should reach a value of constant concentration from $250 \mathrm{~min}$ of reaction time.

However, during this period, despite the $k_{4 d} k_{2}$ and $k_{2} / k_{1}$ ratio values being 4.58 and 10.5 , respectively, the $C_{P h O H}$ is higher than the $C_{H O}$, possibly due to the high benzene fraction, i.e., at the end of $250 \mathrm{~min}$ reaction time, the benzene concentration is 22 times greater than $\mathrm{PhOH}$.

Figure 18 shows a reaction pathway for the photocatalytic hydroxylation of benzene to phenol and its products, with the suggestion of two routes for benzene conversion according to the following steps:

1. Direct Oxidation of benzene by the hole $\left(h_{v b}{ }^{+}\right)$, followed by the reaction of the resulting cation with either a hydroxyl group or water molecules adsorbed superficially, producing phenol.

2. Production of cyclohexadiene radical by addition of the hydroxyl radical to benzene, followed

Table 3. Kinetic constants derived from the proposed mechanism for photocatalytic hydroxylation of benzene.

\begin{tabular}{cc}
\hline \multicolumn{3}{c}{ Kinetic Constants $\left(\mathrm{min}^{-1}\right)$} \\
\hline$k_{1}$ & $3.14 \times 10^{-4}$ \\
$k_{2}$ & $3.29 \times 10^{-3}$ \\
$k_{3}$ & $2.20 \times 10^{-3}$ \\
$k_{4 d}$ & $1.51 \times 10^{-2}$ \\
$k_{4 i}$ & $1.00 \times 10^{-7}$ \\
\hline
\end{tabular}

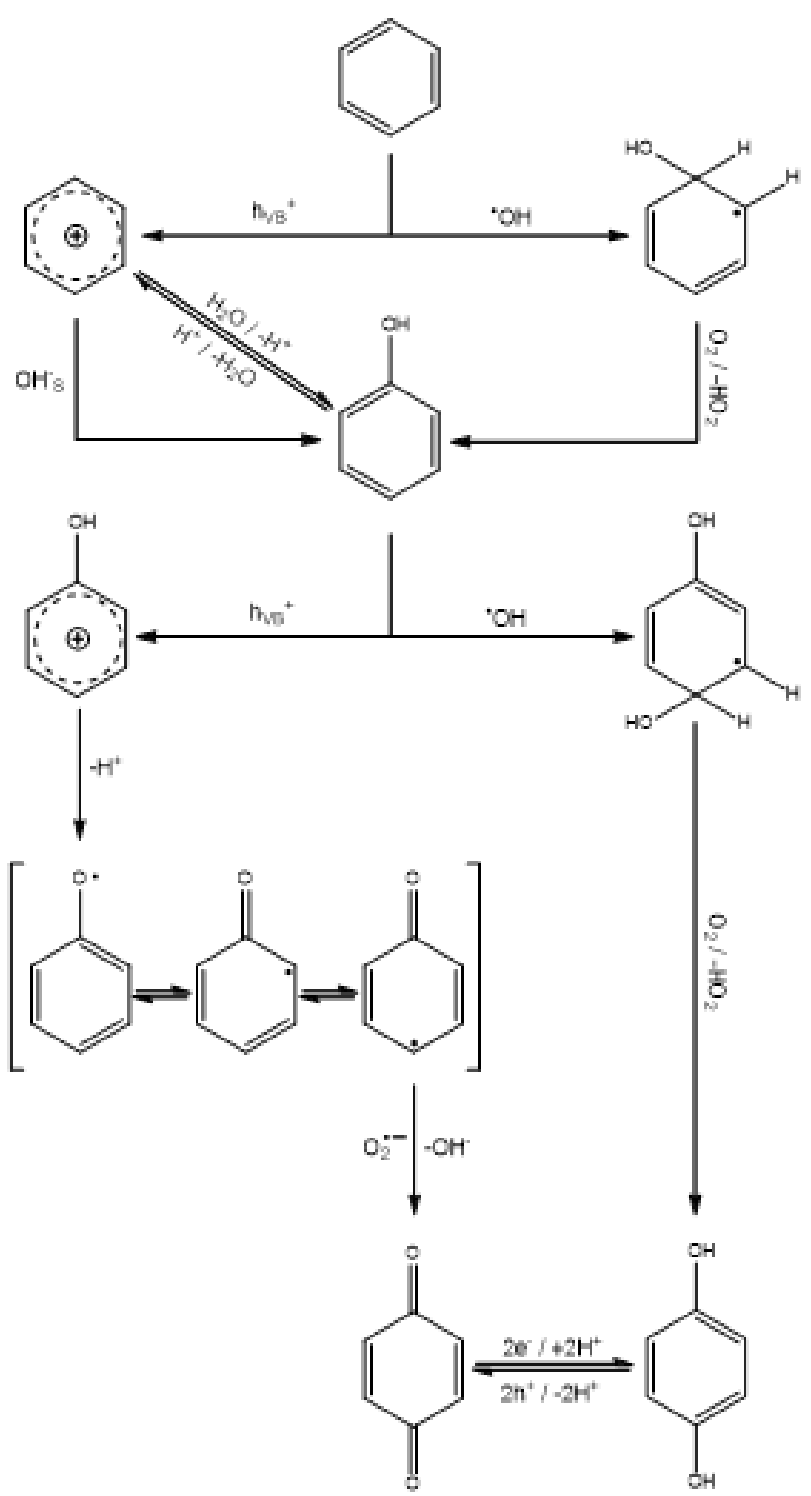

Figure 18. Reaction pathway for photocatalytic hydroxylation of benzene to phenol and its derivatives (d'Hennezel et al., 1998; Zhong et al., 2007).

by abstraction of $\mathrm{H}$ by $\mathrm{O}_{2}$ to generate $\mathrm{HO}_{2} \cdot$ radical and phenol.

Direct Oxidation of phenol by the hole $\left(h_{v b}+\right)$, followed by deprotonation of the resulting phenolic radical and production of the phenoxy radical, which reacts with superoxide radical, producing benzoquinone. It is reported that $\mathrm{HQ}$ and $\mathrm{BQ}$ are in equilibrium when present in aqueous suspension of UV-irradiated $\mathrm{TiO}_{2}$ (d'Hennezel et al. 1998).

Similarly to benzene, phenol can be converted to hydrocyclohexadienyl radical by addition of the hydroxyl radical, with the abstraction of $\mathrm{H}$ by $\mathrm{O}_{2}$ to generate the $\mathrm{HO}_{2} \cdot$ radical and hydroquinone.

In this work, results from the study of the effect of the radicals or hole sequestering agents on the reaction of benzene hydroxylation are not shown. However, it is reasonable to propose, based on the $\mathrm{MB}$ reaction 
data with the values of the kinetic constants (Table 3), that the formation of $\mathrm{PhOH}$ occurs preferably by the action of the hydroxyl radical, due to the stability of benzene. $\mathrm{PhOH}$ is more susceptible to oxidation by the hole action, compared to benzene, in agreement with the relatively high value of $k_{3}$, which is due to HQ formation directly from $\mathrm{PhOH}$.

The value of $k_{2}$ calculated is higher than $k_{3}$ and is consistent since $k$, is related to the action of the hydroxyl radical which is highly reactive; this suggestion is in agreement with the results observed for photocatalytic degradation of MB (Figure 15). In the benzene hydroxylation process, a competitive process between direct oxidation of phenol by the hole $\left(h_{v b}{ }^{+}\right)$and the production of the ${ }^{\circ} \mathrm{OH}$ radical by the hole is suggested. However, $k_{2}$ is favored since the water concentration is higher than phenol.

\section{CONCLUSIONS}

The methodology applied for the synthesis of photocatalytic spheres leads to the production of meso and macroporous material, predominantly, with amorphous characteristic. The material had its photocatalytic activity confirmed by degradation of methylene blue dye, with high stability in the recycling method. Tests with additives suggested that the photocatalytic route for the system is mainly due to the action of hydroxyl radicals. The spheres also demonstrated applicability for the photocatalytic conversion of benzene, resulting in the production of phenol, hydroquinone and benzoquinone. The phenol formation is the rate-determining step for the subsequent production of hydroquinone and benzoquinone.

\section{ACKNOWLEDGEMENTS}

The authors acknowledge the "Federal University of Ceará", Dr. J.M. Sasaki (X-ray Laboratory) for the XRD measurement and, AUXPE - FUNCAP 3024/2013/Process n ${ }^{\circ} 23038008862 / 2013-81$.

\section{REFERENCES}

Adamczyk, A., Długoń, E. The FTIR studies of gels and thin films of $\mathrm{Al}_{2} \mathrm{O}_{3}-\mathrm{TiO}_{2}$ and $\mathrm{Al}_{2} \mathrm{O}_{3}-\mathrm{TiO}_{2}-\mathrm{SiO}_{2}$ systems. Spectrochimica Acta Part A: Molecular and Biomolecular Spectroscopy, 89, 11-17 (2012). https://doi.org/10.1016/j.saa.2011.12.018

Affam, A. C., Chaudhuri, M. Degradation of pesticides chlorpyrifos, cypermethrin and chlorothalonil in aqueous solution by $\mathrm{TiO}_{2}$ photocatalysis. Journal of Environmental Management, 130, 160-165 (2013). https://doi.org/10.1016/j.jenvman.2013.08.058
Ahmed, S., Rasul, M. G., Brown, R., Hashib, M. A. Influence of parameters on the heterogeneous photocatalytic degradation of pesticides and phenolic contaminants in wastewater: a short review. Journal of Environmental Management, 92, 311-330 (2011). https://doi.org/10.1016/j.jenvman.2010.08.028

Anderson, C., Bard, A. J. Improved photocatalytic activity and characterization of mixed $\mathrm{TiO}_{2} / \mathrm{SiO}_{2}$ and $\mathrm{TiO}_{2} / \mathrm{Al}_{2} \mathrm{O}_{3}$ materials. The Journal of Physical Chemistry B, 101, 2611-2616 (1997). https://doi. org/10.1021/jp9626982

Asenjo, N. G., Santamaria, R., Blanco, C., Granda, M., Alvarez, P., Menéndez, R. Correct use of the Langmuir-Hinshelwood equation for proving the absence of a synergy effect in the photocatalytic degradation of phenol on a suspended mixture of titania and activated carbon. Carbon, 55, 62-69 (2013). https://doi.org/10.1016/j. carbon.2012.12.010

Augugliaro, V., Coluccia, S., Loddo, V., Marchese, L., Martra, G., Palmisano, L., Schiavello, M. Photocatalytic oxidation of gaseous toluene on anatase $\mathrm{TiO} 2$ catalyst: mechanistic aspects and FT-IR investigation. Applied Catalysis B: Environmental, 20, 15-27 (1999). https://doi. org/10.1016/S0926-3373(98)00088-5

Bellardita, M., Addamo, M., Di Paola, A., Marcì, G., Palmisano, L., Cassar, L., Borsa, M. Photocatalytic activity of $\mathrm{TiO}_{2} / \mathrm{SiO}_{2}$ systems. Journal of Hazardous Materials, $174,707-713$ (2010). https://doi. org/10.1016/j.jhazmat.2009.09.108

Braga, T. P., Gomes, E. C. C., Sousa, A. F de, Carreño, N. L. V., Longhinotti, E., Valentini, A. Synthesis of hybrid mesoporous spheres using the chitosan as template. Journal of Non-Crystalline Solids, 355, 860-866 (2009a). https://doi.org/10.1016/j. jnoncrysol.2009.04.005

Braga, T. P., Longhinotti, E., Pinheiro, A. N., Valentini, A. Synthesis of hybrid spheres for the dehydrogenation of ethylbenzene in the presence of $\mathrm{CO}_{2}$. Applied Catalysis A: General, 362, 139-146 (2009b). https://doi.org/10.1016/j. apcata.2009.04.034

Buzzo, G. S., Rodrigues, A. C. B., Souza, R. F. B. de, Silva, J. C. M., Bastos, E. L., Spinacé, E. V., Oliveira Neto, A., Assumpção, M. H. M. T. Synthesis of hydroquinone with co-generation of electricity from phenol aqueous solution in a proton exchange membrane fuel cell reactor. Catalysis Communications, 59,113-115 (2015). https://doi. org/10.1016/j.catcom.2014.09.048

Chen, J. Y., Zhou, P. J., Li, J. L., Wang, Y. Studies on the photocatalytic performance of cuprous oxide/ chitosan nanocomposites activated by visible light. Carbohydrate Polymers, 72, 128-132 (2008). https://doi.org/10.1016/j.carbpol.2007.07.036 
Chen, X., Mao, S. S. Titanium Dioxide Nanomaterials : Synthesis, Properties, Modifications, and Applications. Chemical Reviews, 107, 2891-2959 (2007). https://doi.org/10.1021/cr0500535

Chen, Y., Wang, K., Lou, L. Photodegradation of dye pollutants on silica gel supported $\mathrm{TiO} 2$ particles under visible light irradiation. Journal of Photochemistry and Photobiology A: Chemistry, 163, 281-287 (2004). https://doi.org/10.1016/j. jphotochem.2003.12.012

d'Hennezel, O., Pichat, P., Ollis, D. F. Benzene and toluene gas-phase photocatalytic degradation over $\mathrm{H}_{2} \mathrm{O}$ and $\mathrm{HCL}$ pretreated $\mathrm{TiO}_{2}$ : by-products and mechanisms. Journal of Photochemistry and Photobiology A: Chemistry, 118, 197-204 (1998). https://doi.org/10.1016/S1010-6030(98)00366-9

de Cordoba, M. C. F., Matos, J., Montaña, R., Poon, P. S., Lanfredi, S., Praxedes, F. R., HernándezGarrido, J. C., Calvino, J. J., Rodríguez-Aguado, E., Rodríguez-Castellón, E., Ania, C. O. Sunlight photoactivity of rice husks-derived biogenic silica. Catalysis Today, 328, 125-135 (2019). https://doi. org/10.1016/j.cattod.2018.12.008

Fujishima, A., Rao, T. N., Tryk, D. A. Titanium dioxide photocatalysis. Journal of Photochemistry and Photobiology C: Photochemistry Reviews, 1, 1-21 (2000). https://doi.org/10.1016/S13895567(00)00002-2

Gao, E., Wang, W. Role of graphene on the surface chemical reactions of $\mathrm{BiPO}_{4}-\mathrm{rGO}$ with low $\mathrm{OH}$ related defects. Nanoscale, 5, 11248-56 (2013). https://doi.org/10.1039/c3nr03370h

Guibal, E. Interactions of metal ions with chitosanbased sorbents: a review. Separation and Purification Technology, 38, 43-74 (2004). https:// doi.org/10.1016/j.seppur.2003.10.004

Houas, A., Lachheb, H., Ksibi, M., Elaloui, E., Guillard, C., Herrmann, J. M. Photocatalytic degradation pathway of methylene blue in water. Applied Catalysis B: Environmental, 31, 145-157 (2001). https://doi.org/10.1016/S0926-3373(00)00276-9

Hu, C., Tang, Y., Yu, J. C., Wong, P. K. Photocatalytic degradation of cationic blue X-GRL adsorbed on $\mathrm{TiO}_{2} / \mathrm{SiO}_{2}$ photocatalyst. Applied Catalysis B: Environmental, 40, 131-140 (2003). https://doi. org/10.1016/S0926-3373(02)00147-9

Jaroenworaluck, A., Pijarn, N., Kosachan, N., Stevens, R. Nanocomposite $\mathrm{TiO}_{2}-\mathrm{SiO}_{2}$ gel for UV absorption. Chemical Engineering Journal, 181-182, 45-55 (2012). https://doi.org/10.1016/j.cej.2011.08.028

Jiang, R., Zhu, H.-Y., Chen, H.-H., Yao, J., Fu, Y.Q., Zhang, Z.-Y., Xu, Y.-M. Effect of calcination temperature on physical parameters and photocatalytic activity of mesoporous titania spheres using chitosan/poly(vinyl alcohol) hydrogel beads as a template. Applied Surface Science,
319, 189-196 (2014). https://doi.org/10.1016/j. apsusc. 2014.06.185

Jiang, R., Zhu, H., Yao, J., Fu, Y., Guan, Y. Chitosan hydrogel films as a template for mild biosynthesis of $\mathrm{CdS}$ quantum dots with highly efficient photocatalytic activity. Applied Surface Science, 258, 3513-3518 (2012). https://doi.org/10.1016/j. apsusc.2011.11.105

Kadib, A. El., Molvinger, K., Cacciaguerra, T., Bousmina, M., Brunel, D. Chitosan templated synthesis of porous metal oxide microspheres with filamentary nanostructures. Microporous Mesoporous Materials, 142, 301-307 (2011). https://doi.org/10.1016/j.micromeso.2010.12.012

Lee, J.-W., Kong, S., Kim, W.-S., Kim, J. Preparation and characterization of $\mathrm{SiO} 2 / \mathrm{TiO} 2$ core-shell particles with controlled shell thickness. Materials Chemistry and Physics, 106, 39-44 (2007). https:// doi.org/10.1016/j.matchemphys.2007.05.019

Lee, J. W., Othman, M. R., Eom, Y., Lee, T. G., Kim, W. S., Kim, J. The effects of sonification and $\mathrm{TiO}_{2}$ deposition on the micro-characteristics of the thermally treated $\mathrm{SiO}_{2} / \mathrm{TiO}_{2}$ spherical core-shell particles for photo-catalysis of methyl orange. Microporous Mesoporous Materials, 116, 561-568 (2008). https://doi.org/10.1016/j. micromeso.2008.05.017

Li, G., Bai, R., Zhao, X. S. Coating of $\mathrm{TiO}_{2}$ thin films on the surface of $\mathrm{SiO}_{2}$ microspheres: toward industrial photocatalysis. Industrial \& Engineering Chemistry Research, 47, 8228-8232 (2008). https:// doi.org/10.1021/ie800561y

Li, W., Li, D., Zhang, W., Hu, Y., He, Y., Fu, X. Microwave Synthesis of ZnxCd1-xS Nanorods and Their Photocatalytic Activity under Visible Light. The Journal of Physical Chemistry C, 114, 21542159 (2010). https://doi.org/10.1021/jp9066247

Liu, H., Du, Y., Yang, J., Zhu, H. Structural characterization and antimicrobial activity of chitosan/betaine derivative complex. Carbohydrate Polymers, 55, 291-297 (2004). https://doi. org/10.1016/j.carbpol.2003.10.001

Llano, B., Restrepo, G., Marín, J. M., Navío, J. A., Hidalgo, M. C. Characterisation and photocatalytic properties of titania-silica mixed oxides doped with Ag and Pt. Applied Catalysis A: General, 387, 135-140 (2010). https://doi.org/10.1016/j. apcata.2010.08.021

Loddo, V., Marci, G., Martín, C., Palmisano, L., Rives, V., Sclafani, A. Preparation and characterisation of $\mathrm{TiO}_{2}$ (anatase) supported on $\mathrm{TiO}_{2}$ (rutile) catalysts employed for 4-nitrophenol photodegradation in aqueous medium and comparison with $\mathrm{TiO}_{2}$ (anatase) supported on $\mathrm{Al}_{2} \mathrm{O}_{3}$. Applied Catalysis B: Environmental, 20, 29-45 (1999). https://doi. org/10.1016/S0926-3373(98)00089-7 
Mahesh, K. P. O., Kuo, D.-H., Huang, B.-R. Facile synthesis of heterostructured Ag-deposited SiO2@ $\mathrm{TiO} 2$ composite spheres with enhanced catalytic activity towards the photodegradation of $\mathrm{AB} 1$ dye. Journal of Molecular Catalysis A: Chemical, 396, 290-296 (2015). https://doi.org/10.1016/j. molcata.2014.10.017

Maldotti, A., Andreotti, L., Molinari, A., Tollari, S., Penoni, A., Cenini, S. Photochemical and photocatalytic reduction of nitrobenzene in the presence of cyclohexene. Journal of Photochemistry and Photobiology A: Chemistry, 133, 129-133 (2000). https://doi.org/10.1016/ S1010-6030(00)00212-4

Maldotti, A., Molinari, A., Amadelli, R., Carbonell, E., Garcia, H. Photocatalytic activity of MCMorganized $\mathrm{TiO}(2)$ materials in the oxygenation of cyclohexane with molecular oxygen. Photochemical \& Photobiological Sciences, 7, 819-25 (2008). https://doi.org/10.1039/b804377a

Malhotra, B. D., Kaushik, A. Metal oxide-chitosan based nanocomposite for cholesterol biosensor. Thin Solid Films, 518, 614-620 (2009). https://doi. org/10.1016/j.tsf.2009.07.036

Malinowska, B., Walendziewski, J., Robert, D., Weber, J. V., Stolarski, M. The study of photocatalytic activities of titania and titania-silica aerogels. Applied Catalysis B: Environmental, 46, 441451 (2003). https://doi.org/10.1016/S09263373(03)00273-X

Marugán, J., López-Muñoz, M.-J., van Grieken, R., Aguado, J. Photocatalytic Decolorization and Mineralization of Dyes with Nanocrystalline $\mathrm{TiO}_{2} / \mathrm{SiO}_{2}$ Materials. Industrial \& Engineering Chemistry Research, 46, 7605-7610 (2007). https:// doi.org/10.1021/ie070093u

Matos, J., García, A., Park, S. E. Ti-containing mesoporous silica for methylene blue photodegradation. Applied Catalysis A: General, 393, 359-366 (2011). https://doi.org/10.1016/j. apcata.2010.12.020

Matos, J., Llano, B., Montaña, R., Poon, P. S., Hidalgo, M. C. Design of $\mathrm{Ag} /$ and $\mathrm{Pt} / \mathrm{TiO}_{2}-\mathrm{SiO}_{2}$ nanomaterials for the photocatalytic degradation of phenol under solar irradiation. Environmental Science and Pollution Research, 25, 18894-18913 (2018). https://doi.org/10.1007/s11356-018-21023

Nagaveni, K., Hegde, M. S., Ravishankar, N., Subbanna, G. N., Madras, G. Synthesis and structure of nanocrystalline $\mathrm{TiO}_{2}$ with lower band gap showing high photocatalytic activity. Langmuir, 20, 29002907 (2004). https://doi.org/10.1021/la035777v

Ollis, D. F. Kinetics of liquid phase photocatalyzed reactions: An illuminating approach. Journal of Physical Chemistry B, 109, 2439-2444 (2005). https://doi.org/10.1021/jp040236f
Park, H., Choi, W. Photocatalytic conversion of benzene to phenol using modified $\mathrm{TiO}_{2}$ and polyoxometalates. Catalysis Today, 101, 291-297 (2005). https://doi.org/10.1016/j. cattod.2005.03.014

Park, H., Park, Y., Kim, W., Choi, W. Surface modification of $\mathrm{TiO}_{2}$ photocatalystforenvironmental applications. Journal of Photochemistry and Photobiology C: Photochemistry Reviews, 15, $1-20 \quad$ (2013). https://doi.org/10.1016/j. jphotochemrev.2012.10.001

Preethi, T., Abarna, B., Rajarajeswari, G. R. Influence of chitosan-PEG binary template on the crystallite characteristics of sol-gel synthesized mesoporous nano-titania photocatalyst. Applied Surface Science, 317, 90-97 (2014). https://doi. org/10.1016/j.apsusc.2014.07.190

Santos, R. C. R., Pinheiro, A. N., Leite, E. R., Freire, V. N., Longhinotti, E., Valentini, A. Simple synthesis of $\mathrm{Al}_{2} \mathrm{O}_{3}$ sphere composite from hybrid process with improved thermal stability for catalytic applications. Materials Chemistry and Physics, 160, 119-130 (2015). https://doi.org/10.1016/j. matchemphys.2015.04.014

Serpone, N., Dondi, D., Albini, A. Inorganic and organic UV filters: Their role and efficacy in sunscreens and suncare products. Inorganica Chimica Acta, 360, 794-802 (2007). https://doi. org/10.1016/j.ica.2005.12.057

Somashekar, D., Joseph, R., Chitosanases - Properties And Applications: A Review. Bioresource Technology, 55, 35-45 (1996). https://doi. org/10.1016/0960-8524(95)00144-1

Vela, N., Martínez-Menchón, M., Navarro, G., PérezLucas, G., Navarro, S. Removal of polycyclic aromatic hydrocarbons (PAHs) from groundwater by heterogeneous photocatalysis under natural sunlight. Journal of Photochemistry and Photobiology A: Chemistry, 232, 32-40 (2012). https://doi.org/10.1016/j.jphotochem.2012.02.003

Wang, J., Zhao, G., Zhang, Z., Zhang, X., Zhang, G., Ma, T., Jiang, Y., Zhang, P., Li, Y. Investigation on degradation of azo fuchsine using visible light in the presence of heat-treated anatase $\mathrm{TiO}_{2}$ powder. Dyes and Pigments, 75, 335-343 (2007). https:// doi.org/10.1016/j.dyepig.2006.06.007

Wang, X., Du, Y., Ding, S., Fan, L., Shi, X., Wang, Q., Xiong, G. Large two-photon absorbance of chitosan-ZnS quantum dots nanocomposite film. Physica E: Low-dimensional Systems and Nanostructures, 30, 96-100 (2005). https://doi. org/10.1016/j.physe.2005.07.017

Wilhelm, P., Stephan, D. Photodegradation of rhodamine $\mathrm{B}$ in aqueous solution via $\mathrm{SiO}_{2} / \mathrm{TiO}_{2}$ nano-spheres. Journal of Photochemistry and Photobiology A: Chemistry, 185, 19-25 (2007). https://doi.org/10.1016/j.jphotochem.2006.05.003 
Xiao, G., Su, H., Tan, T. Synthesis of core-shell bioaffinity chitosan- $\mathrm{TiO}_{2}$ composite and its environmental applications. Journal of Hazardous Materials, 283, 888-896 (2015). https://doi. org/10.1016/j.jhazmat.2014.10.047

Xin, Y., Liu, H., Han, L., Zhou, Y. Comparative study of photocatalytic and photoelectrocatalytic properties of alachlor using different morphology $\mathrm{TiO}_{2} / \mathrm{Ti}$ photoelectrodes. Journal of Hazardous Materials, 192, 1812-1818 (2011). https://doi.org/10.1016/j. jhazmat.2011.07.005

$\mathrm{Xu}, \mathrm{T} ., \mathrm{Cai}, \mathrm{Y} .$, Shea, K. E. O. Adsorption and Photocatalyzed Oxidation of Methylated Arsenic Species in TiO Suspensions Adsorption and Photocatalyzed Oxidation of Methylated Arsenic Species in $\mathrm{TiO}_{2}$ Suspensions. Environmental Science and Technology, 41, 471-5477 (2007). https://doi.org/10.1021/es0628349

$\mathrm{Xu}, \mathrm{Y}$., Langford, C. H. Variation of Langmuir adsorption constant determined for $\mathrm{TiO}_{2}-$ photocatalyzed degradation of acetophenone under different light intensity. Journal of Photochemistry and Photobiology A: Chemistry, 133, 67-71 (2000). https://doi.org/10.1016/S1010-6030(00)00220-3

Yamashita, H., Kawasaki, S., Ichihashi, Y., Harada, M., Takeuchi, M., Anpo, M., Characterization of titanium-silicon binary oxide catalysts prepared by the sol-gel method and their photocatalytic reactivity for the liquid-phase oxidation of 1-octanol. Journal of Physical Chemistry B, 102, 5870-5875 (1998). https://doi.org/10.1021/jp981343a

Yang, J., Chen, C., Ji, H., Ma, W., Zhao, J. Mechanism of $\mathrm{TiO}_{2}$ - Assisted Photocatalytic Degradation of Dyes under Visible Irradiation: Photoelectrocatalytic Study by $\mathrm{TiO}_{2}$ - Film Electrodes. Journal of
Physical Chemistry B, 109, 21900-21907 (2005). https://doi.org/10.1021/jp0540914

Zhang, G., Yi, J., Shim, J., Lee, J., Choi, W. Photocatalytic hydroxylation of benzene to phenol over titanium oxide entrapped into hydrophobically modified siliceous foam. Applied Catalysis B: Environmental, 102, 132-139 (2011). https://doi. org/10.1016/j.apcatb.2010.11.034

Zhang, L., Xing, Z., Zhang, H., Li, Z., Wu, X. High thermostable ordered mesoporous $\mathrm{SiO}_{2}{ }^{-}$ $\mathrm{TiO}_{2}$ coated circulating-bed biofilm reactor for unpredictable photocatalytic and biocatalytic performance. Applied Catalysis B: Environmental, 180, 521-529 (2016). https://doi.org/10.1016/j. apcatb.2015.07.002

Zhang, M., An, T., Fu, J., Sheng, G., Wang, X., Hu, X., Ding, X. Photocatalytic degradation of mixed gaseous carbonyl compounds at low level on adsorptive $\mathrm{TiO}_{2} / \mathrm{SiO}_{2}$ photocatalyst using a fluidized bed reactor. Chemosphere, 64, 423-431 (2006). https://doi.org/10.1016/j. chemosphere.2005.11.062

Zheng, X., Li, D., Li, X., Yu, L., Wang, P., Zhang, X., Fang, J., Shao, Y., Zheng, Y. Photoelectrocatalytic degradation of rhodamine $\mathrm{B}$ on $\mathrm{TiO}_{2}$ photonic crystals. Physical Chemistry Chemical Physics, 16, 15299-15306 (2014). https://doi.org/10.1039/ C4CP01888E

Zhong, J., Wang, J., Tao, L., Gong, M., Zhimin, L., Chen, Y. Photocatalytic degradation of gaseous benzene over $\mathrm{TiO}_{2} / \mathrm{Sr}_{2} \mathrm{CeO}_{4}$ : Kinetic model and degradation mechanisms. Journal of Hazardous Materials, 139, 323-331 (2007). https://doi. org/10.1016/j.jhazmat.2006.06.036 